\title{
Low-Volatility Vapors and New Particle Formation Over the Southern Ocean During the Antarctic Circumnavigation Expedition
}

\section{Baccarini, Andrea}

2021-11-27

Baccarini , A , Dommen , J , Lehtipalo , K , Henning , S , Modini , R L , Gysel-Beer , M , Baltensperger , U \& Schmale , J 2021 , ' Low-Volatility Vapors and New Particle Formation Over the Southern Ocean During the Antarctic Circumnavigation Expedition ', Journal of Geophysical Research : Atmospheres, vol. 126 , no. 22 , e2021JD035126 . https://doi.org/10.1029/2021JD035126

http://hdl.handle.net/10138/337643

https://doi.org/10.1029/2021JD035126

cc_by_nc_nd

publishedVersion

Downloaded from Helda, University of Helsinki institutional repository.

This is an electronic reprint of the original article.

This reprint may differ from the original in pagination and typographic detail.

Please cite the original version. 


\section{JGR Atmospheres}

\section{RESEARCH ARTICLE \\ 10.1029/2021JD035126 \\ Special Section: \\ Low-Volatility Vapors and New Particle Formation Over the Southern Ocean During the Antarctic Circumnavigation Expedition}

Southern Ocean clouds, aerosols, precipitation and radiation

Key Points:

- Production of methanesulfonic acid occurred predominantly in the condensed phase, followed by enhanced volatilization at lower relative humidity

- The observed new particle formation events were probably driven by sulfuric acid and the environmental conditions (mainly temperature and condensation sink)

- Boundary layer new particle formation over the Southern Ocean in summer occurred very sporadically and does not contribute to the cloud condensation nuclei budget

Supporting Information:

Supporting Information may be found in the online version of this article.

Correspondence to:

J. Schmale,

julia.schmale@epfl.ch

\section{Citation:}

Baccarini, A., Dommen, J., Lehtipalo, K., Henning, S., Modini, R. L., GyselBeer, M., et al. (2021). Low-volatility vapors and new particle formation over the Southern Ocean during the Antarctic Circumnavigation Expedition. Journal of Geophysical Research: Atmospheres, 126, e2021JD035126. https://doi.org/10.1029/2021JD035126

Received 23 APR 2021

Accepted 5 OCT 2021

Author Contributions:

(C) 2021. The Authors

This is an open access article under the terms of the Creative Commons Attribution-NonCommercial-NoDerivs License, which permits use and distribution in any medium, provided the original work is properly cited, the use is non-commercial and no modifications or adaptations are made.

\author{
Andrea Baccarini ${ }^{1,2}$ (D) , Josef Dommen ${ }^{2}$ (D), Katrianne Lehtipalo ${ }^{3,4}$ (i), Silvia Henning ${ }^{5}$ (iD), \\ Robin L. Modini² (D), Martin Gysel-Beer ${ }^{2}$ (D), Urs Baltensperger ${ }^{2}$, and Julia Schmale ${ }^{1}$ (D) \\ ${ }^{1}$ Extreme Environments Research Laboratory, École Polytechnique Fédérale de Lausanne, Lausanne, Switzerland, \\ ${ }^{2}$ Laboratory of Atmospheric Chemistry, Paul Scherrer Institute, Villigen PSI, Switzerland, ${ }^{3}$ Institute for Atmospheric \\ and Earth System Research/Physics, University of Helsinki, Helsinki, Finland, ${ }^{4}$ Finnish Meteorological Institute, \\ Helsinki, Finland, ${ }^{5}$ Institute for Tropospheric Research, Experimental Aerosol and Cloud Microphysics, Leipzig, \\ Germany
}

\begin{abstract}
During summer, the Southern Ocean is largely unaffected by anthropogenic emissions, which makes this region an ideal place to investigate marine natural aerosol sources and processes. A better understanding of natural aerosol is key to constrain the preindustrial aerosol state and reduce the aerosol radiative forcing uncertainty in global climate models. We report the concentrations of gaseous sulfuric acid, iodic acid, and methanesulfonic acid (MSA) together with a characterization of new particle formation (NPF) events over a large stretch of the Southern Ocean. Measurements were conducted on board the Russian icebreaker Akademik Tryoshnikov from January to March 2017. Iodic acid is characterized by a particular diurnal cycle with reduced concentration around noon, suggesting a lower formation yield when solar irradiance is higher. Gaseous MSA does not have a diurnal cycle and measured concentrations in gas and condensed phase are compatible with this species being primarily produced via heterogeneous oxidation of dimethyl sulfide and subsequent partitioning into the gas phase. We also found that NPF in the boundary layer is mainly driven by sulfuric acid but it occurred very rarely over the vast geographical area probed and did not contribute to the cloud condensation nuclei budget in a directly observable manner. Despite the near absence of NPF events in the boundary layer, Aitken mode particles were frequently measured, supporting the hypothesis of a free tropospheric source. Iodic acid and MSA were not found to participate in nucleation, however, MSA may contribute to aerosol growth via heterogeneous formation in the aqueous phase.
\end{abstract}

\section{Introduction}

Aerosols have a major impact on our climate (Stocker et al., 2014). They scatter and absorb solar radiation and are part of cloud formation processes as cloud condensation nuclei $(\mathrm{CCN})$ or ice nucleating particles (INP). The combination of aerosol-radiation and aerosol-cloud interactions contributes the largest fraction of uncertainty to the overall radiative forcing budget (Stocker et al., 2014). The present day (PD) aerosol forcing is calculated against a preindustrial (PI) baseline, which is poorly constrained because direct measurements of PI aerosols are impossible. Additionally, the radiative forcing due to aerosol-cloud interactions $\left(\mathrm{RF}_{\mathrm{aci}}\right)$ is non-linearly dependent on the total aerosol number concentration and is much more sensitive to changes in low concentration regimes, which are more representative of the the PI time (Carslaw et al., 2013, 2017). Therefore, the highly uncertain concentration and distribution of PI aerosols has a disproportionately large effect on the $\mathrm{PD} \mathrm{RF}_{\mathrm{aci}}$ uncertainty. One way to constrain this uncertainty is to better characterize natural sources of aerosols, which were predominant during the PI time. However, there are very few places on Earth that may still resemble PI-like conditions with minimum anthropogenic influence. Among these locations, the Southern Ocean is probably the region with the highest number of PI-like days during summer (Hamilton et al., 2014). Recently, Regayre et al. (2020) demonstrated that a small set of measurements over the Southern Ocean can be as effective as a two orders of magnitude larger and more heterogeneous set of data from the Northern Hemisphere in reducing the $\mathrm{RF}_{\mathrm{aci}}$ in a global climate model. This highlights the value of measurements in pristine and remote locations. 
Conceptualization: Andrea Baccarini, Josef Dommen, Martin Gysel-Beer, Julia Schmale

Data curation: Andrea Baccarini, Josef Dommen, Robin L. Modini, Julia Schmale

Funding acquisition: Josef Dommen, Julia Schmale

Investigation: Andrea Baccarini, Josef Dommen, Katrianne Lehtipalo, Silvia Henning, Robin L. Modini, Julia Schmale

Methodology: Andrea Baccarini, Josef Dommen, Martin Gysel-Beer, Julia Schmale

Supervision: Josef Dommen, Urs Baltensperger, Julia Schmale

Visualization: Andrea Baccarini Writing - original draft: Andrea Baccarini

Writing - review \& editing: Andrea Baccarini, Josef Dommen, Katrianne Lehtipalo, Silvia Henning, Robin L. Modini, Martin Gysel-Beer, Urs Baltensperger, Julia Schmale
The contribution of anthropogenic activities to the aerosol population over the Southern Ocean is small and generally limited to the more northerly sector (Schmale, Baccarini, et al., 2019; Uetake et al., 2020). This implies that natural emissions constitute the overwhelming share of the aerosol population with sea spray and new particle formation from marine emissions presumably being the two main aerosol sources. Other minor sources are volcanic emissions (Schmidt et al., 2012), emissions associated to sea birds and other animals (Legrand et al., 1998; Schmale et al., 2013) and blowing snow from ice covered regions (Frey et al., 2020). The concentration of sea spray aerosol (SSA) is mainly driven by wind speed and sea state and can vary largely across the Southern Ocean (Quinn et al., 2017; Schmale, Baccarini, et al., 2019). Previous measurements in the Southern Ocean reported a contribution between 10\% and $100 \%$ to the total CCN number concentration, depending also on supersaturation (Fossum et al., 2018; Quinn et al., 2017; Schmale, Baccarini, et al., 2019). Ocean biology is also known to affect the SSA aerosol number concentration and hygroscopicity (Collins et al., 2016; Long et al., 2014; Sellegri et al., 2021). However, no direct influence of ocean biology on the SSA total number concentration emerged from the measurements during the Antarctic Circumnavigation Expedition (Landwehr et al., 2021). NPF occurs via the nucleation of low-volatility vapors to form small particles, which eventually grow by condensation of the same or other gaseous compounds. Over the Southern Ocean, NPF is thought to happen mainly via sulfuric acid (Clarke et al., 1998; Gordon et al., 2017; Yoon \& Brimblecombe, 2002), which is formed from the oxidation of dimethyl sulfide (DMS), a biogenic compound produced in the water by phytoplankton. During the austral summer the concentration of DMS in the water of the Southern Ocean is the highest of the planet (Lana et al., 2011), with high fluxes into the atmosphere and potentially producing high concentrations of sulfuric acid. However, under typical boundary layer conditions the concentration of sulfuric acid is too low to form particles alone, and another molecule, such as ammonia, is required to stabilize the nucleating clusters (Kirkby et al., 2011). Jokinen et al. (2018) reported the first molecular characterization of NPF from Aboa station $\left(73.0364{ }^{\circ} \mathrm{S}, 13.4109^{\circ} \mathrm{W}\right)$ in Antarctica, showing that new particles are formed via nucleation of sulfuric acid and ammonia. Sources of ammonia over the Southern Ocean are related to animals, mainly bird or seal colonies, which are known to be strong local sources of ammonia (Riddick et al., 2012, 2016; Schmale et al., 2013). The concentration of ammonia over the open ocean is poorly constrained and is expected to be lower than over coastal Antarctica. However, Altieri et al. (2021) reported mixing ratios of tens of ppt across the Atlantic Southern Ocean, comparable to the estimates from Jokinen et al. (2018) in Aboa. More recently, Brean et al. (2021) showed that NPF around the Antarctic peninsula is driven by sulfuric acid and alkylamines, with the ice-covered Weddell Sea being the main source region for alkylamines. These results are consistent with previous studies reporting that the sea ice region around Antarctica is enriched in alkylamines and other organic nitrogen molecules, which were also found both in primary and secondary aerosol (Dall'Osto et al., 2017, 2019; Decesari et al., 2020; Rinaldi et al., 2020). Another potentially important compound for NPF in this region is iodine, which is known to form new particles via iodic acid nucleation (Baccarini et al., 2020; He et al., 2021; Sipilä et al., 2016). Iodine concentrations can be very high in Antarctica and iodine monoxide mixing ratios exceeding 20 ppt have been reported in coastal Antarctica (Saiz-Lopez et al., 2007; Schönhardt et al., 2008).

Previous studies in Antarctica (Jang et al., 2019; Järvinen et al., 2013; Jokinen et al., 2018; Kim et al., 2019; Lachlan-Cope et al., 2020; Weller et al., 2015) and over the Southern Ocean (Brean et al., 2021; Dall'Osto et al., 2017; Heintzenberg et al., 2004; Humphries et al., 2015) have shown that airmasses during NPF events frequently originated from sea ice regions or from above the boundary layer. Some field studies have observed a higher concentration of nucleation mode sized particles in the free troposphere (Clarke \& Kapustin, 2002; Clarke et al., 1998; McCoy et al., 2021; Sanchez et al., 2021; Weber et al., 1998) and proposed that NPF may occur predominantly in the free troposphere in the outflow of clouds. Here, formation rates can be higher because of the lower temperatures and smaller condensation sink. Newly formed particles can then be entrained in the boundary layer following for example the passage of cold fronts (Gras et al., 2009; Jimi et al., 2008). These results are also supported by modeling studies suggesting that typical marine boundary layer conditions are unfavorable for NPF (Katoshevski et al., 1999; Pirjola et al., 2000; Korhonen et al., 2008; Revell et al., 2019; Yoon \& Brimblecombe, 2002). However, global climate models also tend to underestimate both the Aitken mode aerosol concentration (Hodshire et al., 2019) and the CCN number (Chambers et al., 2018; McCoy et al., 2020; Schmale, Baccarini, et al., 2019) over the Southern Ocean, pointing toward a missing aerosol source or an inaccurate process representation (e.g., too strong deposition velocity) in the models. The underestimation of Aitken mode particles is particularly relevant because NPF is believed to be 
the largest source of particles in this size range (MÅrtensson et al., 2010; Seinfeld \& Pandis, 2016; Spracklen et al., 2007). The reason for this discrepancy is still not known and additional process based measurements over the Southern Ocean are required to better understand the sources and distribution of aerosols.

An important process that is often overlooked is DMS oxidation, which is generally implemented in models without considering heterogeneous chemistry. This is particularly relevant for methanesulfonic acid (MSA), an oxidation product of DMS, which can be more efficiently produced in the aqueous phase than in the gas phase (Q. Chen et al., 2018; Hoffmann et al., 2016) and increases the mass of aerosols activated in cloud droplets (cloud processing). MSA constitutes a large fraction of the secondary aerosol mass over the Southern Ocean, up to 50\% compared to the non-sea-salt sulphate aerosol mass (Preunkert et al., 2007; Yan et al., 2019), but its contribution to the $\mathrm{CCN}$ budget has not been quantified so far.

In this work, measurements of low-volatility vapors and the observations of NPF events during the Antarctic Circumnavigation Expedition (ACE) will be presented. In particular, we measured the concentration of sulfuric acid, MSA and iodic acid together with naturally charged ions and newly formed aerosol particles. In the Methods (Section 2) we provide details on the expedition, the instruments used and the methodology adopted to treat the data. The results and discussion (Section 3) is divided into three parts. The first part provides a broad overview of the results with a focus on sulfuric acid, iodic acid and MSA distribution over the Southern Ocean. In the second part we provide a detailed analysis on sources and processes controlling the MSA concentration, both in the gas and in the condensed phase. The third part is centered around NPF with a presentation of the events detected during ACE, a characterization of the nucleating vapors and a description of the most relevant drivers for the formation of new particles. The conclusions (Section 4) summarizes our results and put them into perspective.

\section{Methods}

The Antarctic Circumnavigation Expedition took place between December 2016 and March 2017, sailing around Antarctica across the Southern Ocean on board of the Russian icebreaker Akademik Tryoshnikov. The expedition was divided into 3 legs:

1. Leg 1: from Cape Town (South Africa) to Hobart (Tasmania) [December 20, 2016- January 19, 2017]

2. Leg 2: from Hobart (Tasmania) to Punta Arenas (Chile) [January 22, 2017-February 22, 2017]

3. Leg 3: from Punta Arenas (Chile) to Cape Town (South Africa) [February 26, 2017-March 19, 2017],

with several stops around islands and other points of interest during the voyage. A detailed description of the voyage is reported in Schmale, Baccarini, et al. (2019) and in the cruise report (Walton \& Thomas, 2018).

We measured sulfuric acid, MSA and iodic acid using a nitrate Chemical Ionization Atmospheric Pressure interface Time-of-Flight Mass Spectrometer (CI-APi-ToF) (Baccarini et al., 2019a, 2019b, 2021a; Jokinen et al., 2012). During some periods the chemical ionization inlet was removed and the instrument was operated as an APi-ToF to exclusively characterize the chemical composition of naturally charged ions (Junninen et al., 2010). The concentration and size distribution of newly formed and Aitken mode particles were obtained using a Neutral cluster and Air Ion Spectrometer (NAIS) (Baccarini et al., 2021b; Mirme \& Mirme, 2013). The NAIS measures ions from about 0.8 to $40 \mathrm{~nm}$ and neutral particles from about 2 to $40 \mathrm{~nm}$. The particle size distribution (PSD) was measured using a Scanning Mobility Particle Sizer (SMPS) and an Aerodynamic Particle Sizer (APS), together covering a size range from $11 \mathrm{~nm}$ to $19 \mu \mathrm{m}$ (Schmale et al., 2019a, 2019b). The PSDs obtained from these two different instruments were combined using a mode-fitting technique similar to Modini et al. (2015). The results of the mode-fitting procedure were used to estimate the aerosol number concentration in the different modes and to calculate the condensation sink following Dal Maso et al. (2002). Standard meteorological variables, such as air temperature, wind speed and wind direction were measured with different sensors both on the portside and on the starboard side of the ship as described by Landwehr et al. (2019).

Aerosols and gases were sampled from three different inlets mounted on a container, which was located on the second deck of the ship at a height of about $15 \mathrm{~m}$ above the ocean surface. Two of the inlets (the ones used for standard aerosol and trace gas measurements) consisted of heated $2 \mathrm{~m}$ long vertical stainless 
steel tubes of $2.54 \mathrm{~cm}$ outer diameter (OD) and a specifically designed top-cover for isokinetic sampling of particles up to $40 \mu \mathrm{m}$ in diameter, following the Global Atmosphere Watch recommendations for aerosol sampling (Weingartner et al., 1999). Conductive tubing was used to connect the aerosol instrumentation to the main inlets inside the container. A third inlet was specifically designed for short residence time of the sampled air to improve detection of low-volatility vapors and newly formed particles. This inlet was a simple $1.5 \mathrm{~m}$ long stainless steel tube of $5 \mathrm{~cm}$ inner diameter and a $\mathrm{U}$-shaped bend at the end to prevent rain from entering. It was not heated. The (CI)-APi-ToF and the NAIS were sampling behind this third inlet and were operated only during Leg 2 and Leg 3. The (CI)-APi-ToF was connected directly to the main inlet with a straight vertical $40 \mathrm{~cm}$ long stainless steel tube $(1.9 \mathrm{~cm}$ OD, $10 \mathrm{lpm}$ flow rate). The NAIS was connected to the main inlet with a $190 \mathrm{~cm}$ long stainless steel tube $\left(3.5 \mathrm{~cm}\right.$ OD, $60 \mathrm{lpm}$ flow rate), containing three $90^{\circ}$ bends. Losses through the (CI)-APi-ToF and NAIS sampling lines were calculated theoretically following Kulkarni et al. (2011) whereas for the other aerosol instruments the losses were experimentally characterized using size selected polystyrene latex particles. A more detailed description of the measurement set-up is provided in the cruise report (Walton \& Thomas, 2018) and in Schmale, Baccarini, et al. (2019).

The CI-APi-ToF was calibrated for sulfuric acid at the end of the campaign with a series of experiments at the Paul Scherrer Institute (PSI) smog chamber (Paulsen et al., 2005), yielding a calibration constant of:

$$
C_{A C E}=6.9 \times 10^{9}[-50 \%+100 \%] \text { molecule } \mathrm{cm}^{-3},
$$

with the calibration uncertainty being indicated in the square brackets. The same calibration constant was used to quantify MSA and iodic acid based on the assumption that the ionization proceeds at the kinetic limit for species that have a lower proton affinity than nitric acid as in these cases. The large uncertainty on the calibration coefficient accounts for the variability of measurement conditions and the fact that the calibration was performed after the campaign. A description of the CI-APi-ToF and its calibration is reported in the Text S1 in Supporting Information S1.

The nitrate CI-APi-ToF is designed to work with a constant addition of nitric acid to the sheath flow in order to produce the reagent ions which are used to ionize the sample air. During ACE, the instrument was operated without an active addition of nitric acid due to a technical problem which was identified only at the end of the expedition. Still the background concentration of nitric acid, desorbing from the walls of the inlet lines, was enough to produce a sufficiently high reagent ion concentration like in a regularly operated nitrate CI-APi-ToF. This was confirmed by the sulfuric acid calibration, which is comparable with previously reported values (Jokinen et al., 2012; Kürten et al., 2012). However, the nitric acid concentration was probably not high enough to take up all the charges produced by the photoionizer. Therefore, reactions with other ions like $\mathrm{O}_{2}^{-}$and $\mathrm{CO}_{3}{ }^{-}$also occurred inside the nitrate $\mathrm{CI}-\mathrm{APi}-\mathrm{ToF}$ inlet. These other reactions led to the production of $\mathrm{SO}_{5}{ }_{5}$ and $\mathrm{HSO}_{4}{ }^{-}$from ambient $\mathrm{SO}_{2}$, which interfered with the detection of ambient sulfuric acid. A detailed characterization of this issue was performed with experiments at the PSI smog chamber and at the CLOUD chamber at CERN. Unfortunately, because the background production of $\mathrm{HSO}_{4}^{-}$was not constant and depended strongly on the instrument settings, such as the inlet flow and voltages, it was not possible to correct for it within a reasonable uncertainty. Therefore, all sulfuric acid values reported in this work are uncorrected and should be considered as upper limit estimates.

Gases and aerosol particles generated by the ship exhaust and other campaign related activities (e.g., helicopter flights) were identified and separated from the background measurement data. As described in Schmale, Baccarini, et al. (2019), data were filtered using a method based on particle number, black carbon and $\mathrm{CO}_{2}$ concentrations leading to a removal of about $50 \%$ of the data for the entire expedition. However, there are also species that are not produced by the ship exhaust, like MSA and iodic acid. Figure 1 shows sulfuric acid, MSA and iodic acid data in clean and polluted conditions by means of violin plots, together with box and whiskers for a concise statistic summary. A violin plot represents the distribution of the data using a kernel density estimate (Hintze \& Nelson, 1998). As expected, sulfuric acid was clearly affected by the ship exhaust with much higher concentrations during polluted conditions, whereas iodic acid was not.

A special situation is found for MSA which showed a cluster of high values (larger than $10^{8}$ molecules $\mathrm{cm}^{-3}$ ) during a polluted period. However, this was a single event where pollution and high MSA occurred coincidentally, but without the pollution causing the high concentration. The event was investigated but it remains unknown why MSA concentrations were so high, because no clear relationship with any external 


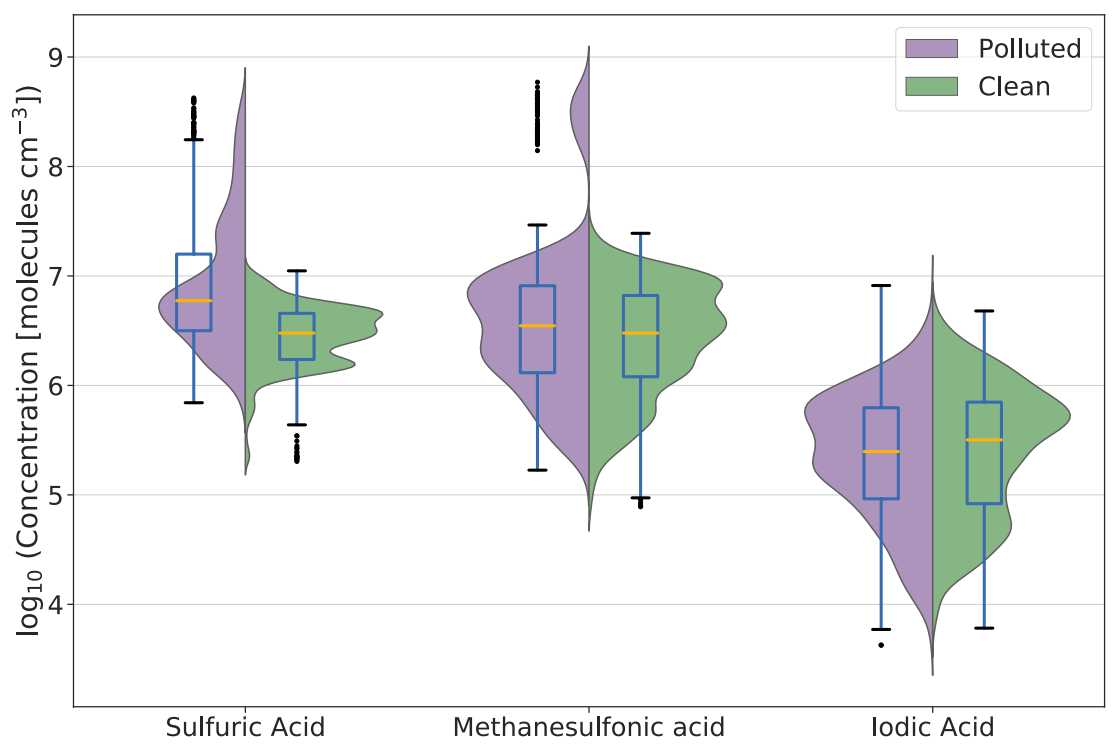

Figure 1. Violin, and box and whiskers plots of sulfuric acid, methanesulfonic acid and iodic acid divided into clean and polluted conditions. Here, polluted means that the measurements were affected by the exhaust of the research vessel. Polluted periods were identified according to the pollution mask developed by Schmale, Baccarini, et al. (2019). The box extends from the first quartile (Q1) to the third quartile (Q3) with a line indicating the median. The whiskers are set to $1.5 \times[\mathrm{Q} 3-\mathrm{Q} 1]$.

variable was identified. Data from this event were not considered for further analysis because their validity is uncertain.

Even if MSA and iodic acid are not directly emitted by the ship exhaust they could still be affected by the higher aerosol concentration within the exhaust plume which acts as a condensation sink and can reduce the concentration of low-volatility vapors. This effect is not evident from the data distribution shown in Figure 1, however, there are periods where emissions from the ship reduce the concentration of gaseous MSA and iodic acid. Figure S1 in Supporting Information S1 shows an example of this: during pollution (gray shadowing) there are clear spikes in the sulfuric acid and $\mathrm{SO}_{5}^{-}$signal (which is produced from $\mathrm{SO}_{2}$ ) and in some cases dips in the MSA and iodic acid traces. However, these dips are not always present and generally less pronounced than the pollution spikes, explaining why the overall data distribution seems to be unaffected by pollution. Therefore, given that the effect of pollution on reducing the concentration of MSA and iodic acid is minor, both polluted and clean data were included in the following analysis (except for the single high-concentration event of MSA mentioned above).

We identified NPF events based on the analysis of the particle and ion size distribution below $10 \mathrm{~nm}$ from the NAIS, after excluding the influence from ship exhaust. In particular, only periods with an increase of the sub-10 nm particle concentration larger than a factor of 3 compared to the baseline were considered as NPF events. The sub-10 nm particle concentration baseline was calculated using a $2 \mathrm{hr}$ average before and after each potential event. We also excluded cases where the increase in the sub-10 $\mathrm{nm}$ concentration could be attributed to a tail of the Aitken mode based on a visual inspection of the PSD. Regarding the identification of the ship exhaust influence, we used a less conservative approach compared to the standard pollution mask applied to the gas-phase data (originally developed by Schmale, Baccarini, et al. (2019)) because some of the NPF event would have been classified as polluted despite their natural origin. Individual NPF events were inspected to assess their natural origin by looking at the wind direction, the particle number concentration and the overall particle size distribution. In particular, the wind direction had to be outside of the polluted sector (defined as a $120^{\circ}$ angle centered around a line connecting the sampling inlet with the chimney of the ship, which translates to a relative wind direction between $150^{\circ}$ and $270^{\circ}$ ), while the particle concentration in different size ranges was analyzed to assess if the increase of particles smaller than $\sim 10 \mathrm{~nm}$ originating from NPF was associated to an increase of larger particles potentially coming from the ship exhaust (ship emissions are typically characterized by a bimodal size distribution with both a nucleation and an Aitken 


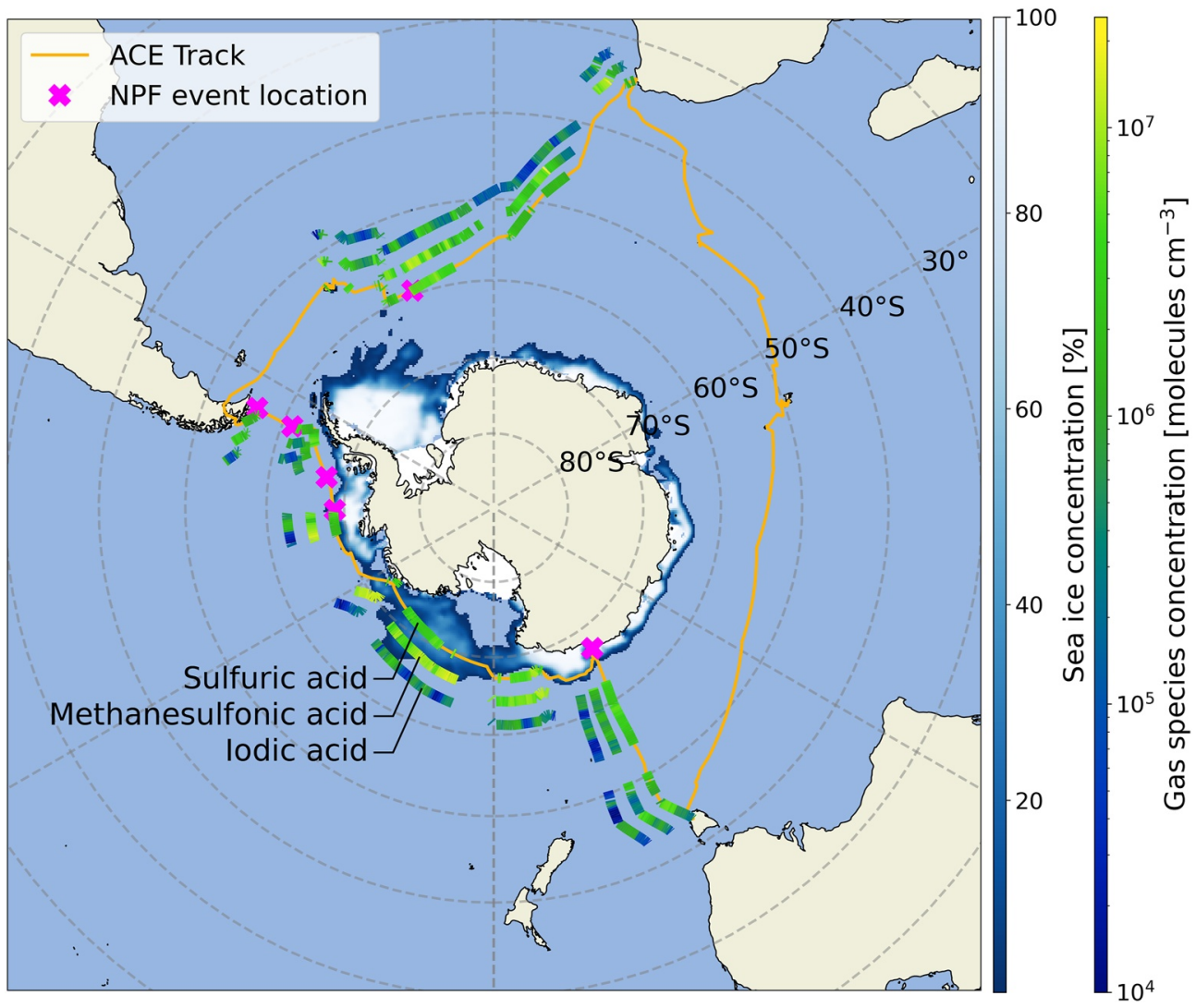

Figure 2. Map showing the track of the expedition and concentrations of sulfuric acid, methanesulfonic acid (MSA) and iodic acid. The concentration of the gas species is reported with color coded lines on a logarithmic scale, showing 1-h median values. The location of the new particle formation events is also reported together with the sea ice concentration (fraction of covered surface) retrieved for January 2017 (Maslanik \& Stroeve, 1999). The MSA and iodic acid data were shifted on the map for better visualization. There are no data available for Leg 1 because the CI-APi-ToF and the NAIS were not operated.

mode (Ovaska et al., 2019)). The size distribution of both particles and ions was also qualitatively inspected to identify the presence of features which could hint at an influence from the ship exhaust, such as the lack of the ion cluster band (small ions are typically scavenged inside the ship plume because of the higher coagulation sink), large differences between the positive and the negative ion size distributions (the aerosol population emitted by the ship often does not reach a charge equilibrium because of the short distance between the chimney and the inlet) and other rapid changes in the PSD. Pollution spikes of short duration during NPF events where identified based on the concentration of particles larger than $30 \mathrm{~nm}$ (we set a threshold of 500 particles $\mathrm{cm}^{-3}$ ) and removed from the PSD figures for graphical reasons.

\section{Results and Discussion}

\subsection{Overview of ACE Results}

Here, we first introduce Figures 2-6 briefly to provide an overview of the main results and then, below, discuss in detail the implications following from them. Figure 2 shows an overview map with the expedition track, 6-h averages of sulfuric acid, MSA and iodic acid concentration measurements and the location of NPF events, which will be described in Section 3.3. The same set of data is also reported in Figures $3 \mathrm{a}$ and $3 \mathrm{~b}$ together with the air temperature as hourly averages. Gaps in the data indicate either instrumental problems or periods when the instrument was operated as an APi-ToF. The time is given in the UTC time-zone here and in the rest of this manuscript, unless specified differently. Additionally, in Figure 4 the distribution 


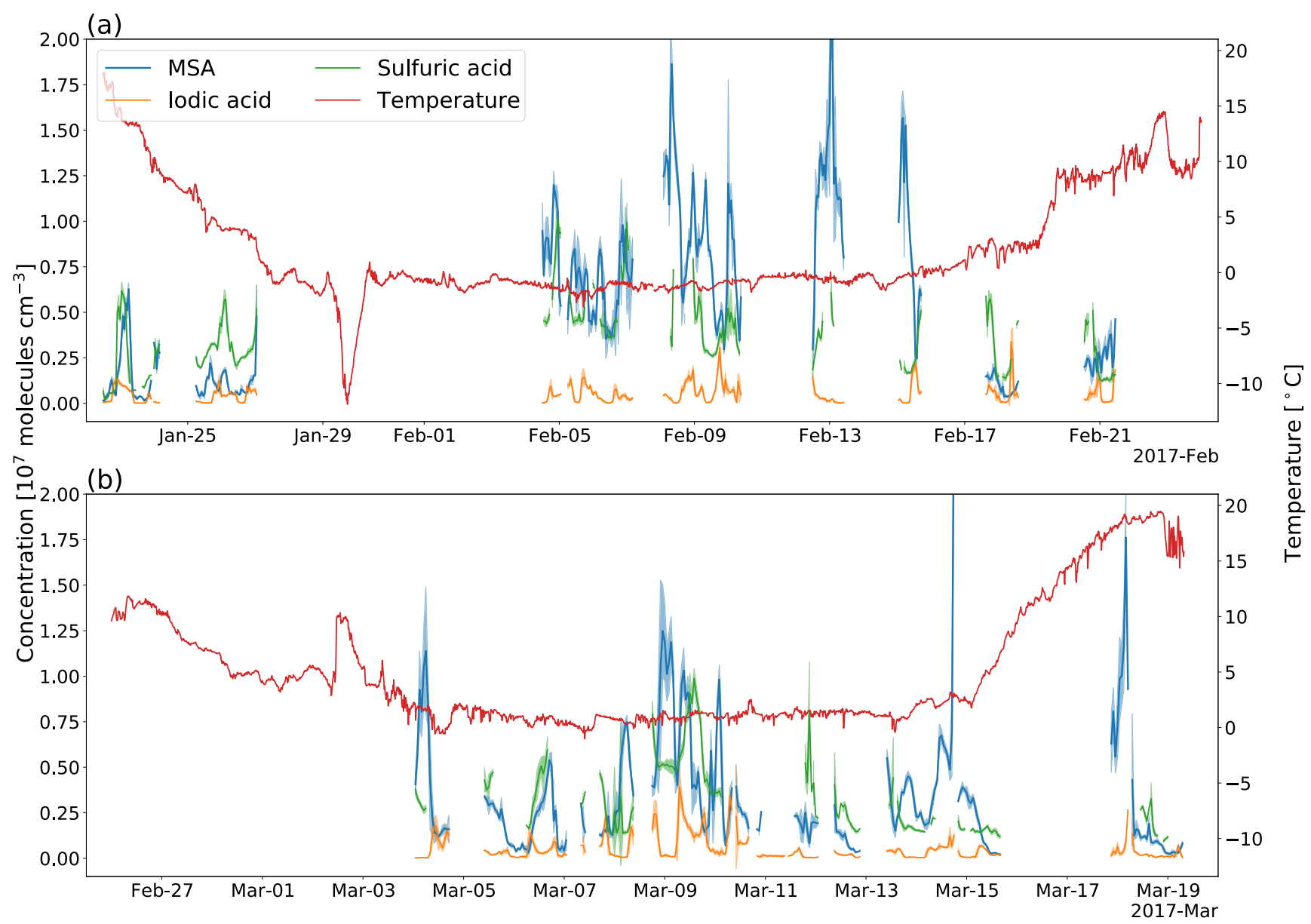

Figure 3. Time series of sulfuric acid, methanesulfonic acid and iodic acid (left axis). Solid lines represent hourly mean values and the shaded envelopes around these lines represent \pm 1 standard deviation. Temperature is shown on the right axis. (a) Leg 2 data and (b) Leg 3 data.

of the data divided into two latitudinal ranges (above and below $60^{\circ} \mathrm{S}$ ) is reported. These two latitudinal bands can be classified as Antarctic and Subantarctic regions (Nowlin \& Klinck, 1986).

Figure 5 illustrates the day and night time data distributions of the trace gases under consideration by means of violin, and box and whiskers plots. The separation between day and night is based on the solar irradiance (SIR) data (night is when SIR is null and day when SIR is larger than $10 \mathrm{Wm}^{-2}$ ). Additionally, Figure 6 depicts the diurnal cycles of the data, which were binned according to the local time. We identified the local noon based on the maximum height of the sun above the horizon and the data were shifted accordingly before the diurnal averaging. This procedure was necessary to avoid artifacts due to the eastward movement of the ship, which caused a continuous shift of the local time with respect to UTC. Moreover, the different latitudes at which the measurements were performed had an effect on the day duration, which can affect the width of the diurnal profiles. To investigate this effect, we also calculated the diurnal profiles separately for measurements above and below $60^{\circ} \mathrm{S}$ as reported in Figure S2 in Supporting Information S1. It is evident that the latitudinal variation does not strongly determine the diurnal evolution of the investigated species but it has an effect on their absolute values (MSA and to a smaller extent also sulfuric acid are higher in more southerly latitudes). The fact that latitude does not have a noticeable effect on the diurnal distribution of the data can probably be explained by solar irradiance being lower at higher latitudes and compensating for the longer duration of the days (Figure S2d in Supporting Information S1).

The main results, which can be inferred from these overview figures regarding the spatial and temporal distribution of gaseous sulfuric acid, MSA and iodic acid over the Southern Ocean, are: 


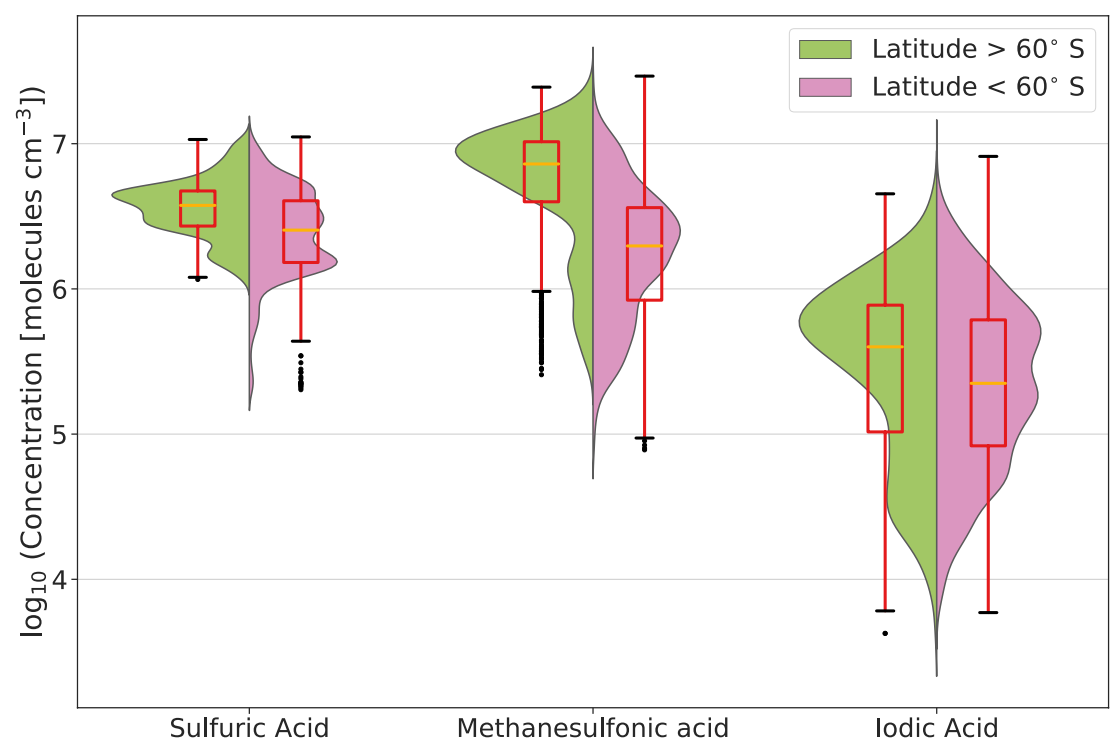

Figure 4. Violin, and box and whiskers plots of sulfuric acid, methanesulfonic acid and iodic acid separated by latitude. Measurements south and north of $60^{\circ} \mathrm{S}$ are representative of Antarctic and Subantarctic conditions, respectively. The box extends from the first quartile (Q1) to the third quartile (Q3) with a line indicating the median. The whiskers are set to $1.5 \times[\mathrm{Q} 3-\mathrm{Q} 1]$.

Sulfuric acid shows a clear diurnal cycle with higher concentration during midday. This result is consistent with sulfuric acid being predominantly produced via photo-oxidation of $\mathrm{SO}_{2}$ and is in line with previous measurements in several marine environments (Berresheim et al., 2002; Lucas, 2002; Mauldin et al., 1999) and in Antarctica (Jefferson, Tanner, Eisele, \& Berresheim, 1998; Mauldin et al., 2003). On the other hand, its night time values are surprisingly high; this could be an indication of a night time production mechanism as previously suggested (Lucas, 2002; Mauldin et al., 2003) or more likely an indication of the instrumental background sulfuric acid production problem described above. Nevertheless, it is safe to assume that the sulfuric acid increase during day time hours is not driven by the instrument background production

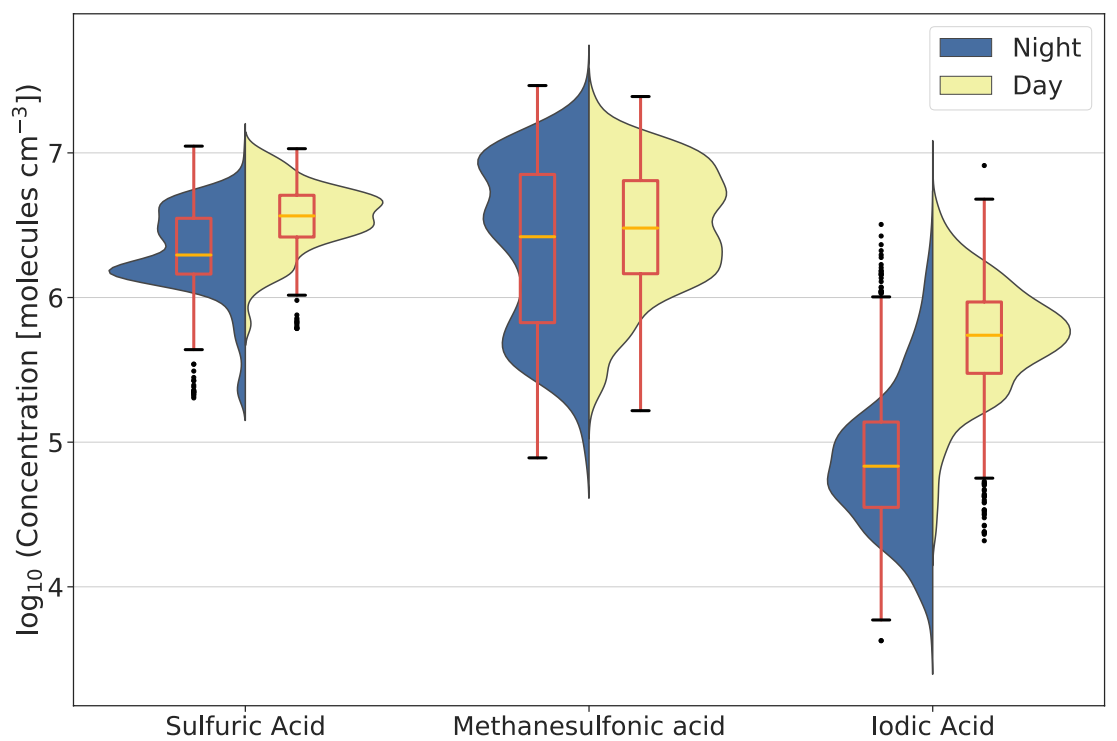

Figure 5. Violin, and box and whiskers plots of sulfuric acid, methanesulfonic acid and iodic acid separated by day and night. The separation was done based on the solar irradiance (SIR) value, with night being SIR $=0 \mathrm{Wm}^{-2}$ and day SIR $>10 \mathrm{Wm}^{-2}$. The box extends from the first quartile (Q1) to the third quartile (Q3) with a line indicating the median. The whiskers are set to $1.5 \times[\mathrm{Q} 3-\mathrm{Q} 1]$. 


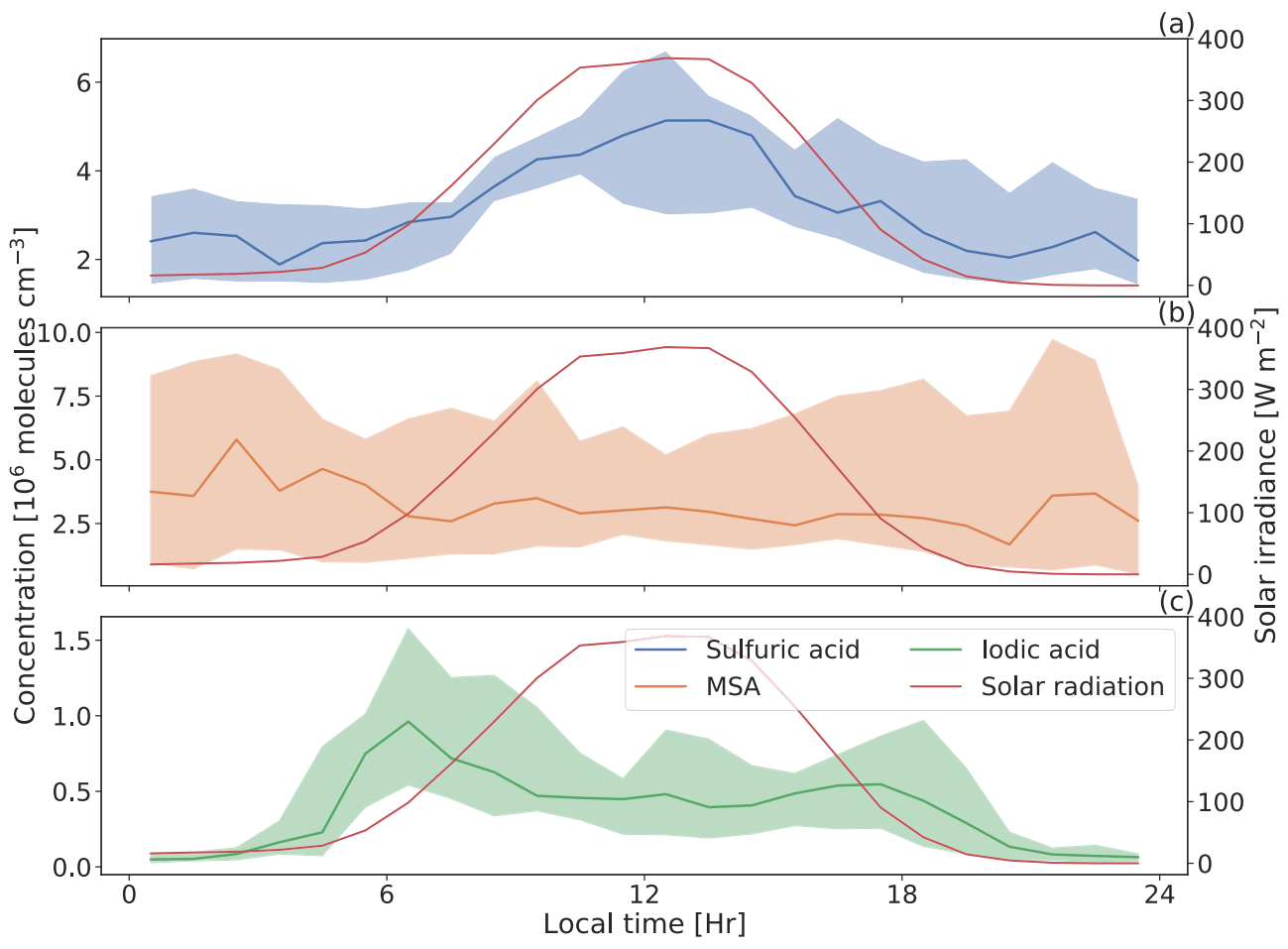

Figure 6. Diurnal profiles of (a) sulfuric acid, (b) methanesulfonic acid and (c) iodic acid. The thick line represents the median and the shaded area the interquartile range. Data were binned using local time determined by the sun height above the horizon. The red line is the solar irradiance median with values on the right axis.

because $\mathrm{SO}_{2}$ does not have a diurnal cycle as confirmed by the $\mathrm{SO}_{5}^{-}$measurements (Figure $\mathrm{S} 3$ in Supporting Information S1). Finally, the sulfuric acid concentration was higher in the region around Antarctica, which is a more biologically productive region characterized by higher DMS concentration in the water (Lana et al., 2011). However, the $\mathrm{SO}_{5}^{-}$signal was also higher in this region, which may indicate a larger sulfuric acid instrumental background. Therefore, these variations must be interpreted with caution.

MSA does not show any diurnal cycle and the distribution of the data is very similar between day and night, the only difference being the presence of a lower concentration mode during night time (Figure 5). This lower concentration mode is likely related to periods of high RH, where the partitioning of MSA is shifted toward the condensed phase. This topic will be analyzed in more detail in the next section. While previous observations already reported that gaseous MSA has a weak to non-existent diurnal cycle (Lucas, 2002; Mauldin et al., 1999), this study is the first to show it on a large regional scale. The absence of a clear MSA diurnal cycle suggests that photochemical production from DMS oxidation is only of minor importance, in line with recent modeling work, which proposed that the largest fraction of MSA is produced in the aqueous phase (Q. Chen et al., 2018; Hoffmann et al., 2016). Condensed phase MSA could then be followed by partitioning to the gas phase. The MSA concentration is also higher close to Antarctica, like sulfuric acid, with a distribution peaking at around $10^{7}$ molecules $\mathrm{cm}^{-3}$ and the median being about 3.7 times higher compared to the Subantarctic region (Figure 4). As described, the region around Antarctica is characterized by higher DMS concentrations which could probably explain the higher MSA concentration. Additionally, higher latitudes correspond to lower temperatures, which increase the MSA production yield from DMS oxidation compared to $\mathrm{SO}_{2}$ production (Barnes et al., 2006). We will provide a more detailed analysis of MSA variability and its sources over the Southern Ocean in Section 3.2.

Iodic acid is characterized by a peculiar diurnal cycle peaking at dawn and dusk with a minimum around noon and very low concentration during night time (the median is below $10^{5}$ molecules $\mathrm{cm}^{-3}$ ). This indicates the presence of a photochemical source and no production during night. Although the formation mechanism of iodic acid is still not well understood, it is known that iodic acid is formed from the iodine radical, which is photochemically produced from precursor molecules like $\mathrm{I}_{2}, \mathrm{HOI}$ or $\mathrm{CH}_{2} \mathrm{I}_{2}$ (Gómez Martín 


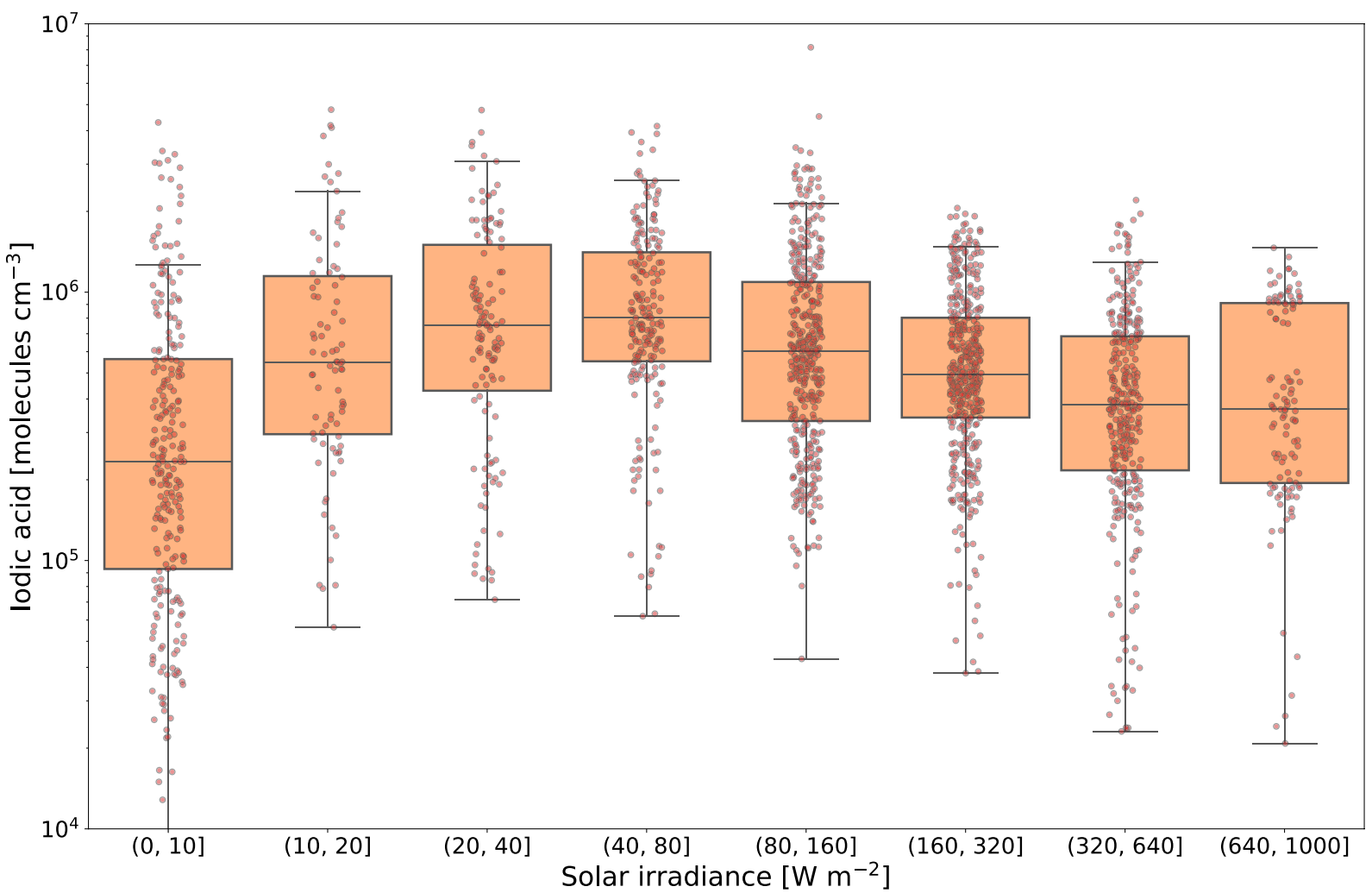

Figure 7. Iodic acid box and whiskers plots as a function of solar irradiance (SIR). Data were binned into different SIR classes as indicated by the axis label. The original data are shown with the small semi-transparent circles. The box extends from the first quartile (Q1) to the third quartile (Q3) with a line indicating the median. The whiskers are set to $1.5 \times[\mathrm{Q} 3-\mathrm{Q} 1]$.

et al., 2020; He et al., 2021; Saiz-Lopez et al., 2012) and this is consistent with the observations reported here. Figure 7 shows the iodic acid concentration binned by SIR to illustrate the effect of solar radiation. This plot shows that the highest iodic acid concentration is measured when SIR is between 20 and $80 \mathrm{Wm}^{-2}$ and decreases for higher values up to $1000 \mathrm{Wm}^{-2}$. The diminished concentration around noon (high SIR) does not have any obvious explanation and it has not been reported before. Two possible hypotheses are (a) that a precursor of iodic acid is reacted away by the $\mathrm{OH}$ and/or the $\mathrm{HO}_{2}$ radicals, which have higher concentrations during noon, or (b) that iodic acid or one of its precursors are photolabile and are photolyzed during the day. Without a proper understanding of iodic acid formation it is not possible to discriminate between the aforementioned processes. However, Gómez Martín et al. (2020) proposed that iodic acid may be formed from IO or $\mathrm{I}_{2} \mathrm{O}_{3}$, where both molecules are photolabile in the near-UV (Lewis et al., 2020; Saiz-Lopez et al., 2012) and a reduced concentration of IO during midday has also been predicted (Saiz-Lopez et al., 2014, 2015). Therefore, photolysis is probably the reason for the reduced iodic acid concentration at higher SIR values. This phenomenon may have consequences on the latitudinal and seasonal distribution of iodic acid and its contribution to NPF. He et al. (2021) demonstrated that iodic acid does not require the presence of $\mathrm{OH}$ to form; ozone and the iodine radical are sufficient. The amount of solar radiation reaching the surface is generally enough to photolyze $I_{2}$ even when the atmospheric optical depth is high (e.g., the sun is low over the horizon), meaning that the most favorable conditions for iodic acid formation may be at high latitudes or during early morning/late afternoon. This observation is consistent with recent studies in the Arctic reporting iodic acid NPF in spring and autumn (Baccarini et al., 2020; Beck et al., 2021). Regarding the latitudinal distribution in the Southern Ocean, iodic acid does not show any evident geographical pattern and the data distribution is similar in the Antarctic and Subantarctic regions. It is interesting to note that iodic acid was not enhanced around the coast of Antarctica, despite previous studies showing exceptionally high concentrations of other iodine oxides near coastal Antarctica (Saiz-Lopez et al., 2007; Schönhardt et al., 2008). This difference is not necessarily a discrepancy considering that different iodine oxides, measured in different years and locations, are compared. However, this is a topic that deserves further attention 
considering the importance of iodic acid for NPF in other locations (Baccarini et al., 2020; Beck et al., 2021; Sipilä et al., 2016).

\subsection{Sources and Processes Controlling MSA Concentration}

In the previous section we tentatively explained the absence of a diurnal cycle in the concentration of gaseous MSA by the fact that DMS photoxidation is likely not the dominant source of MSA over the Southern Ocean. However, the lifetime of gaseous MSA should also be considered because the atmospheric concentration is controlled by both sources and sinks. MSA is a stable molecule which does not react further under typical tropospheric conditions (Barnes et al., 2006). Therefore, its major sinks are condensation to pre-existing aerosol surfaces and dry deposition to the ocean. Previous studies have treated MSA condensation similar to sulfuric acid, assuming kinetic condensation with different accommodation coefficients (Ammann et al., 2013; Berresheim et al., 2002; De Bruyn et al., 1994; Hanson, 2005) varying from about 0.2 to 1 and obtaining a typical lifetime of $40 \mathrm{~min}$ or lower (Berresheim et al., 2002, 2014). Using the same approach for the ACE data leads to a median and interquartile (IQR) range of the MSA lifetime equal to $55(39 ; 79)$ minutes for an accommodation coefficient of 0.2 , and $23(16 ; 30)$ minutes for an accommodation coefficient of 1 . In both cases, the lifetime is relatively short and a decrease in the concentration of MSA during night time would be expected if photooxidation were the dominant source, which was generally not observed. We estimated the lifetime of gaseous MSA against dry deposition to the ocean to be around $22 \mathrm{hr}$ during ACE, which is much longer than the estimated condensation timescales. We calculated dry deposition lifetime by assuming an average boundary layer height of $800 \mathrm{~m}$ as reported by Schmale, Baccarini, et al. (2019) and a deposition velocity of $1 \mathrm{~cm} \mathrm{~s}^{-1}$, which is the typical value for nitric acid over the ocean (Seinfeld \& Pandis, 2016). Nitric acid and MSA should have a similar deposition velocity as they are equally soluble in water (Seinfeld \& Pandis, 2016).

A possible source of gasous MSA which could explain the absence of a diurnal cycle is evaporation of MSA from the condensed phase. Previous studies already hypothesized that MSA may evaporate from particles, especially at low relative humidity (RH) (Berresheim et al., 2002; Mauldin et al., 1999). More recently, Hodshire et al. (2019) provided a parametrization of MSA equilibrium vapor pressure using the Extended Aerosol Inorganics Model (Wexler \& Clegg, 2002) and showed that MSA could behave both as a non-volatile or semi-volatile species depending on the environmental conditions (temperature and relative humidity) and aerosol acidity. This is an important result, which can be used to represent more accurately the partitioning of MSA between the gas and the particle phase. However, in the work of Hodshire et al. (2019) only the MSA to ammonia ratio was used to evaluate the role of particle acidity without considering the role of other compounds.

The gaseous MSA concentration during ACE follows a trend similar to previous studies (Berresheim et al., 2002; Davis et al., 1998; Jefferson, Tanner, Eisele, Davis, et al., 1998; Mauldin et al., 1999) with higher values at lower RH and temperature. Figure 8 shows the gaseous MSA concentration as a function of relative humidity with data separated between day and night for two different parts of the ACE transect. We isolated these two different periods to reduce confounding factors due to the intrinsic variability of the data set; they correspond to transects in a defined latitudinal range and with small temperature variations. The first period extends from February 4 to February 17, 2017 and includes measurements very close to the Antarctic continent with a temperature median and IQR of $-0.8(-1.3 ;-0.3){ }^{\circ} \mathrm{C}$ The second period lasts from March 4 to March 14, 2017. It is more representative of Subantarctic conditions and was characterized by a temperature median and IQR of $1.1(0.8 ; 1.4){ }^{\circ} \mathrm{C}$. The number of MSA measurement points contained in these two periods is similar ( 80 and $89 \mathrm{hr}$ of measurements, respectively) and corresponds in total to about $2 / 3$ of the entire MSA data set. The same plot of gaseous MSA as a function of RH for the full ACE data set is reported in Figure S4 in Supporting Information S1. Both Figure 8 and Figure S4 in Supporting Information S1 show a clear increase of gaseous MSA with decreasing RH, most notably during night time. Focusing on Figure 8, in the first period the decrease is evident only for RH greater than $90 \%$ and $95 \%$ for day and night time, respectively. The second period, instead, is characterized by a more continuous decrease of MSA with increasing RH during night, whereas the trend in the day time data is less clear. In Figure S5 of Supporting Information S1, we show the same as in Figure 8, but exclusively using data when ship exhaust 
(a)

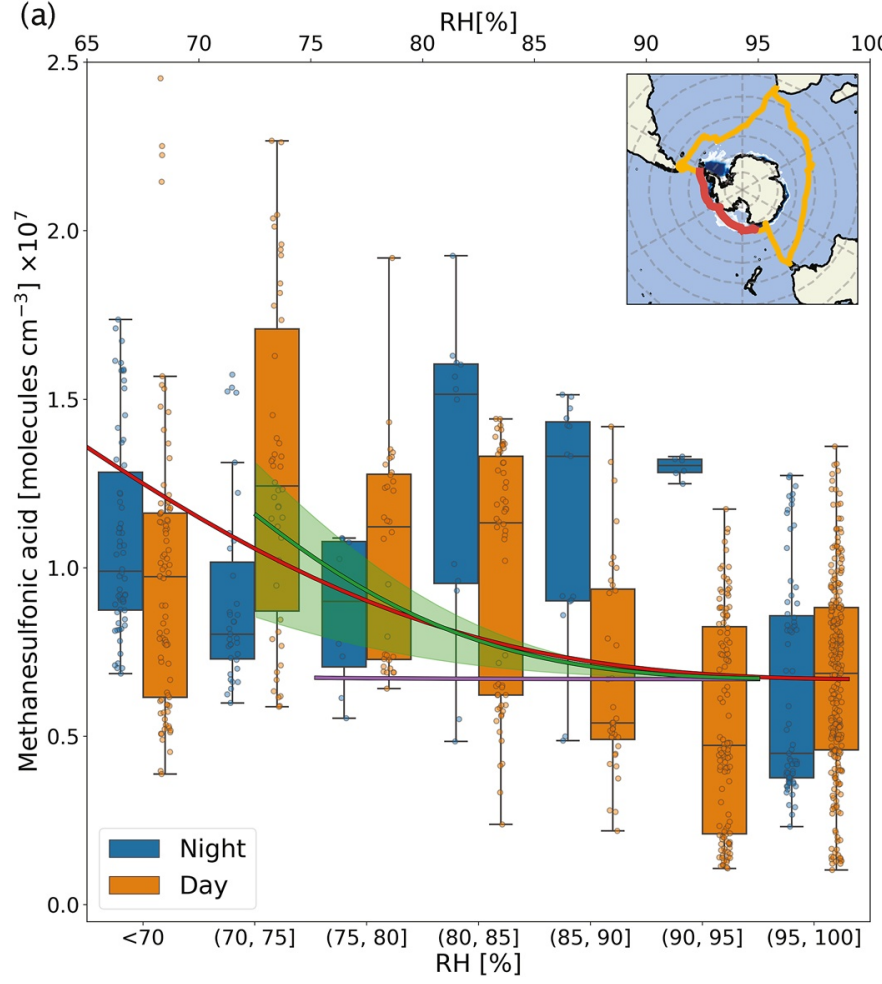

(b)

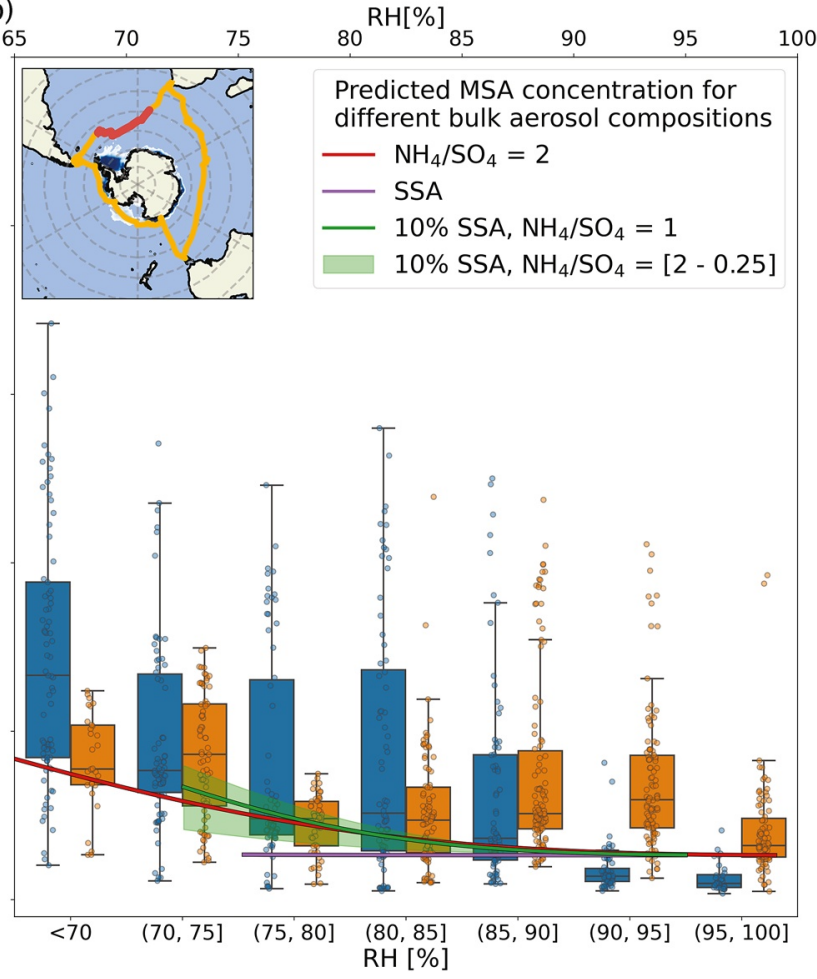

Figure 8. Gaseous methanesulfonic acid (MSA) box and whiskers plot as a function of relative humidity (RH) during two different transects in (a) Leg 2 and (b) Leg 3. Data were separated between day and night and binned into different RH classes as indicated by the axis label. The original data are shown with the small semitransparent circles. The red line in the inset map illustrates the region over which data were collected. The box extends from the first quartile (Q1) to the third quartile (Q3) with a line indicating the median. The whiskers are set to 1.5×[Q3-Q1]. The solid lines in the plots are the predicted MSA gas phase concentrations by partitioning models for different simplified bulk aerosol compositions and as a function of RH (axis on the top). The red line refers to a fully neutralized aerosol system including only sulphate, ammonium and MSA. The purple line relates to a system containing also sea spray aerosol (SSA), in this case the chloride, sodium and sea spray sulphate median concentrations from Antarctic Circumnavigation Expedition (ACE) were used. The green line and shadowed region refer to a system with only $10 \%$ of the SSA concentration measured during ACE and varying ammonium concentrations to mimic different degrees of neutralization. The model used for the simulation cannot account for supersaturated solutions when including also sodium and chloride, therefore the two simulations with SSA stop at higher RH because of aerosol efflorescence.

influence was absent. Results show that the increasing trend of MSA with lower RH persists, confirming that results in Figure 8 including all data are not affected by pollution.

We used the Extended Aerosol Inorganics Model (E-AIM, http://www. aim.env.uea.ac.uk/aim/aim.php, last access: April 22, 2021) (Clegg et al., 1998; Friese \& Ebel, 2010; Wexler \& Clegg, 2002) to investigate if MSA partitioning could explain the increased MSA gaseous concentration at lower RH. E-AIM is a thermodynamic model which allows to calculate the equilibrium of gas, liquid and solid phases for an aqueous aerosol system. The system can be composed of several inorganic ions and organic components (the organic properties must be defined by the user) and probe different environmental conditions (temperature and $\mathrm{RH}$ ). We used ion chromatography data of daily $\mathrm{PM}_{10}$ filter samples (Tatzelt et al., 2020) as input for the chemical composition in E-AIM. Non-sea-salt (nss) sulphate and ammonium in the $\mathrm{PM}_{10}$ filters were clearly affected by the ship exhaust, and therefore only a subset of the filters (23 over a total of 91 filters) with minimum contamination was considered as explained in the Text S2 of Supporting Information S1. Figure S6 in Supporting Information S1 reports the concentrations of the major ions in the selected subset of filters. The mass concentration is dominated by sodium and chloride as expected given the large abundance of sea spray aerosols during ACE (Schmale, Baccarini, et al., 2019). The nss-sulphate to ammonium ratio points toward a large degree of neutralization (the molar ratio median and IQR are 0.57 and $0.40-0.63$, respectively). Previous studies in the Southern Ocean and coastal Antarctica have reported generally more acidic aerosols but there is a large range of variability with the nss-sulphate to ammonium ratio varying between 0.5 and 2 and in few cases even larger values (Barbaro et al., 2017; Legrand et al., 1998; Quinn et al., 1998; 
Savoie et al., 1993; Schmale et al., 2013; Teinilä et al., 2000; Xu et al., 2013; Zorn et al., 2008). It is also important to mention that we do not have any information about the aerosol mixing state but there is likely an external mixture with SSA being predominantly in the coarse mode and compounds of secondary origin (i.e., nss-sulphate, ammonium and MSA) in the accumulation mode (Berg et al., 1998; Jourdain \& Legrand, 2002; Quinn et al., 1998; Xu et al., 2013). However, a certain degree of mixing between the secondary material and the SSA component is also expected as confirmed by measurements of internally mixed MSASSA particles in the Southern Ocean (Yan et al., 2020). E-AIM treats all aerosol components as homogeneously mixed and cannot account for different mass size distributions. Therefore, in order to test the effect of the aerosol composition and mixing state on MSA partitioning we simulated three different systems: (I) a system composed only of nss-sulphate, MSA and different concentrations of ammonium, (II) a system dominated by SSA with the sodium and chloride concentration based on the daily $\mathrm{PM}_{10}$ filter values, (III) a mixed system composed of sulphate, MSA, ammonium and only $10 \%$ of the SSA concentration measured during ACE. The first system is representative of the accumulation mode with only secondary material, the second system of the entire $\mathrm{PM}_{10}$ composition while the third system accounts for a partial mixing between secondary and primary material. This last system represents roughly the submicron aerosol fraction and is probably the most representative of the real atmospheric composition. Details on the E-AIM simulations are reported in the Text S2 of Supporting Information S1.

Based on the E-AIM results we estimated the MSA concentration that would partition to the gas phase as a function of RH. Figure 8 shows the results for the two transects presented before, where the reference value for the condensed phase concentration in each period was taken to be equal to the median concentration from the respective $\mathrm{PM}_{10}$ filter data. Additionally, we shifted the simulated gas phase concentration data by an amount equal to the measured gas phase MSA median concentration above $95 \% \mathrm{RH}$, based on the assumption that at this high RH there would be no repartitioning of MSA from the condensed phase as shown by all simulations. The first system composed of nss-sulphate, ammonium and MSA can reproduce the observed values only for a fully neutralized aerosol; a more acidic aerosol composition would lead to a much higher gas phase MSA concentration (as shown in Figure S7 in Supporting Information S1), which is not compatible with our observations. On the other hand, for the system with the full SSA aerosol concentration all MSA would stay in the condensed phase with negligible evaporation (in the case of a deliquesced aerosol). The third system produces results that are most in agreement with the observed trend. In this case the nss-sulphate to ammonium ratio has a much smaller influence on MSA partitioning compared to the first system. This result can be explained by the combination of three factors: (a) the overall aerosol acidity is reduced by the SSA components, (b) SSA is more hygroscopic and takes up more water and (c) the higher total aerosol mass retains more MSA in the condensed phase. The small effect of the nss-sulphate to ammonium ratio on MSA partitioning is consistent with our results considering that we observed a comparable increase of MSA at low RH in two very different regions of the Southern Ocean (panel a and $\mathrm{b}$ in Figure 8). The first region being closer to the Antarctic coast and characterized by potentially higher ammonia emission compared to the second which was characterized by more open ocean conditions where aerosol particles are typically more acidic (Legrand et al., 1998; Zorn et al., 2008). The same effect can be observed also in the gas to particle MSA ratio as shown in Figure 9. In fact, the gas to particle MSA ratio during the two transects is essentially equivalent despite the different MSA absolute values. The median and IQR gas to particle ratio in the first period are 0.0047 and $(0.0031 ; 0.0085)$, while in the second period they are 0.0054 and $(0.0028 ; 0.0084)$. An aspect that remains unclear is the concentration of gaseous MSA at high RH: for values larger than about $90 \%$ the partitioning model would predict a gaseous MSA concentration more than one order of magnitude lower compared to the measurements. During the day this difference can be explained by gas phase production, which may be the dominant source of gaseous MSA at high $\mathrm{RH}$, but there is no clear explanation for the night time values. A possible source of error is the choice of MSA thermodynamic properties in E-AIM, which suffers from a large degree of uncertainty, as explained in Supporting Information S1. For example, a reduction in the Henry's law constant would directly affect MSA partitioning, producing higher concentrations in the gas phase. However, this change would affect the gas phase concentration across the entire RH range, leading to unrealistically high values at low RH. The simple approach adopted in this work to describe the aerosol chemical composition and mixing state also has an effect on the simulation results and probably contributes to this discrepancy. The role of organics, for example, was neglected but it is known that SSA is enriched in organics (Quinn et al., 2014) and that 


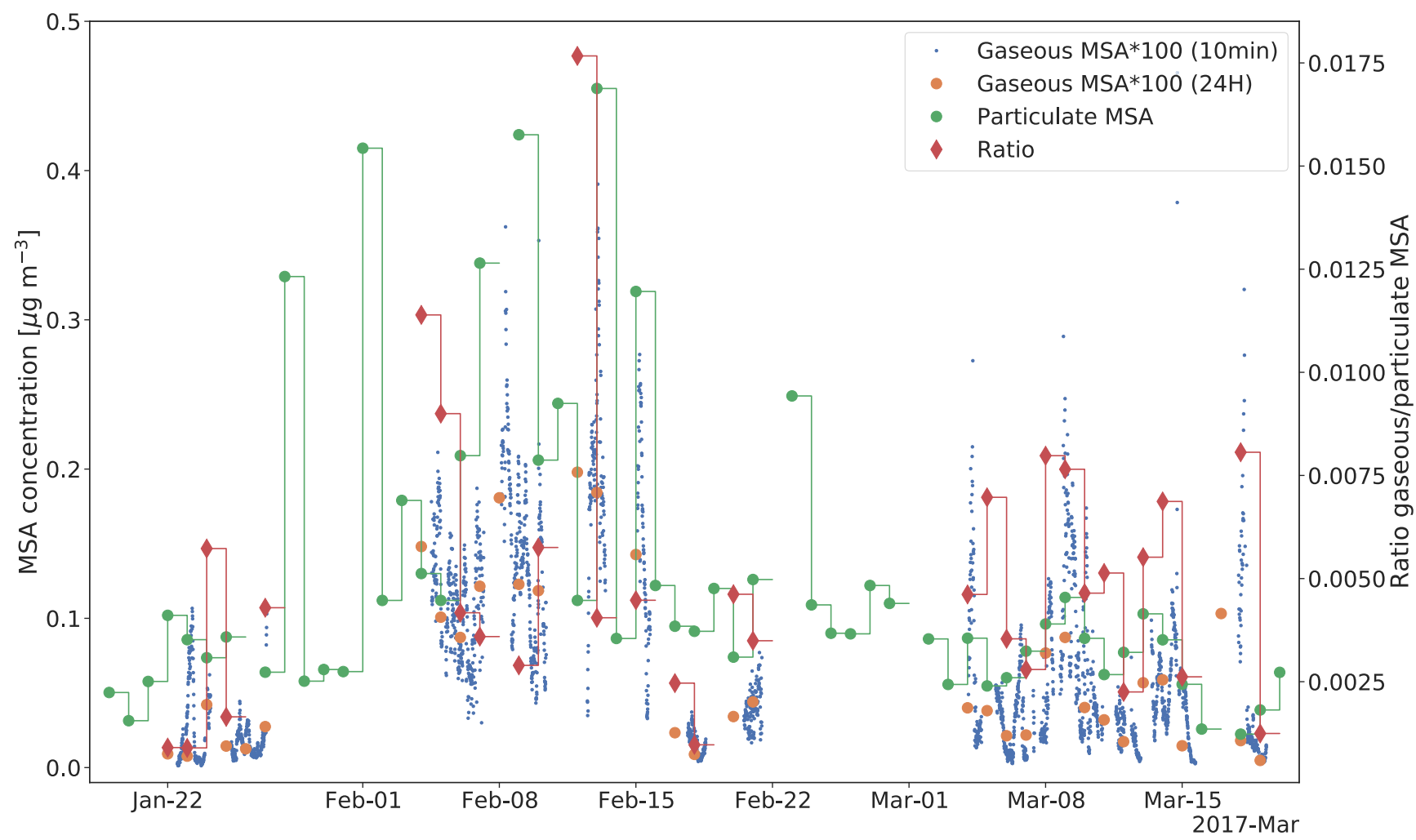

Figure 9. Methanesulfonic acid (MSA) concentrations in the gas and particulate phase, gaseous MSA was multiplied by a factor 100 so that the same scale as for particulate MSA could be used. The ratio between gaseous and particulate MSA is reported on the right axis.

secondary organics can represent an important fraction of the submicron mass. Previous measurements in the Southern Ocean reported a variable contribution of non-MSA organics to the submicron fraction with values up to about $20 \%$ of the total submicron mass (Rinaldi et al., 2020; Virkkula et al., 2006; Zorn et al., 2008). The effect of organic-inorganic interactions on the acidity of aerosol particles is still poorly understood (Pye et al., 2020) but there are certain species, like amines or organic acids, that can directly impact the aerosol pH. Both amines and organic acids (i.e., carboxylic acids) have been detected in the Southern Ocean (Dall'Osto et al., 2017; Decesari et al., 2020), but their contribution to the aerosol pH is probably negligible: the reported concentration of amines is about one order of magnitude lower than ammonia while organic acids are generally weak acids and would not contribute to the $\mathrm{pH}$ of acidic aerosol particles (Pye et al., 2020). Therefore, the partitioning of MSA and the acidity of aerosol particles over the Southern Ocean are most likely driven by inorganic species, but the role of organics should be investigated further to better understand their contribution.

Our model is clearly a simplification with no pretension to be exhaustive. However, it is based on fundamental thermodynamic calculations and provides support to the hypothesis of MSA evaporating from the condensed phase at low RH. To our knowledge, the only indications about MSA partitioning from the condensed phase are based on field observations and on thermodynamic modeling similar to those presented in this work, but dedicated experiments are missing. An accurate characterization of MSA equilibrium vapor pressure as a function of aerosol acidity would be highly valuable to improve our understanding of MSA partitioning in a realistic aerosol and its contribution to the total aerosol mass.

As described before and shown in Figure 9, we measured a low gas to particle MSA ratio during the entire campaign, around $0.5 \%$ on average. These low ratios are in line with previous measurements around coastal Antarctica (Jefferson, Tanner, Eisele, Davis, et al., 1998) and tropical regions (Davis et al., 1999; Mauldin et al., 1999) and seem to support modeling studies predicting that MSA is predominantly formed via aqueous phase oxidation of DMS (Hoffmann et al., 2016; Q. Chen et al., 2018). In order to investigate this hypothesis we calculated the time required to grow the particulate MSA concentration from gas phase 
condensation. This is only a qualitative calculation considering that daily averages were used and that MSA was treated as irreversibly condensing to the particles, which is not true as already described. However, our estimate is still valuable because it provides a lower time limit, as condensation cannot be faster than this. Figure S8 in Supporting Information S1 shows the result in terms of the number of hours that would be required to grow the observed particulate MSA concentration. Two different accommodation coefficients of 0.2 and 1 were used to reproduce the range of values reported in the literature (De Bruyn et al., 1994; Hanson, 2005). Even in the fastest case, when an accommodation coefficient of one is assumed, the typical time required to reproduce the observed particulate MSA is about 3 days, which is equal or even longer than the typical lifetime of an aerosol in the marine BL (e.g., a previous study estimated a lifetime of 2 days for a $0.1 \mu \mathrm{m}$ diameter particle over the Indian Ocean (Williams et al., 2002)).

In conclusion, measurements of gaseous MSA concentrations conducted during ACE show a lack of a diurnal cycle and an increase at low RH which can be explained by evaporation of MSA from the condensed phase and a low contribution from gas phase oxidation of DMS. Additionally, the low gas to particle MSA ratio consistently supports the hypothesis that MSA is predominantly produced in the aqueous phase as predicted by different modeling studies (Q. Chen et al., 2018; Hoffmann et al., 2016).

\subsection{New Particle Formation Over the Southern Ocean}

The frequency of NPF events observed during ACE was low with the events lasting only a few hours and newly formed particles not growing above $10 \mathrm{~nm}$. The only exception are two events, which occurred on two consecutive days in the proximity of the Mertz glacier $\left(67.1^{\circ} \mathrm{S}, 145.0^{\circ} \mathrm{E}\right)$. In this case newly formed particles grew above $10 \mathrm{~nm}$, reaching $20 \mathrm{~nm}$ and forming a clear nucleation mode. All the other events were local bursts of newly formed particles, which disappeared shortly after the nucleation onset. Figure 10 illustrates the particle and negative ion size distributions corresponding to the 2 intense NPF events, solar irradiance and the number concentration of particles larger than $7 \mathrm{~nm}$. A Roman numeral indicates the event number, in this and all the other figures. Unfortunately, for these events no information concerning the chemical composition of the nucleating vapor is available due to a malfunctioning of the mass spectrometer. Both events have a clear diurnal pattern, with particles being produced during the day, suggesting the involvement of sulfuric acid. However, the first and most intense NPF event starts very early in the morning which could also be compatible with the iodic acid diurnal profiles measured during the campaign (Figure 6). Hence it is not possible to uniquely determine the NPF mechanism. The ion size distribution shows some peculiar bands between 2 and $4 \mathrm{~nm}$, these are probably wind generated ions as similar features have been observed at other snow-covered sites at high wind speeds (X. Chen et al., 2017; Manninen et al., 2010), but it is not clear if they were involved in the NPF process. The effect of wind is shown in Figure S9 in Supporting Information S1, which reports both the negative and positive ion size distribution together with wind speed, relative wind direction and distance to land. It is evident that these ion bands are present only for wind speeds larger than about $10 \mathrm{~m} \mathrm{~s}^{-1}$ in close proximity to land, suggesting that blowing snow may be involved as reported by X. Chen et al. (2017).

These two NPF events were interrupted by several short pollution periods. However, the natural origin of nucleation is ensured by the continuous growth of new particles under persistently strong wind conditions with a prevalent wind direction from the clean sector (i.e., the bow of the ship as shown in Figure S9 in Supporting Information S1).

Figure 11 shows two other NPF events, which are representative of the local NPF type detected during the expedition. Here, mass spectrometric measurements are available. These two events have again a diurnal evolution and the measurement of the neutral molecules and charged clusters suggest an involvement of sulfuric acid. It is known that, in this temperature range, sulfuric acid alone cannot lead to NPF at these low concentrations and a stabilizing compound is needed (e.g., ammonia or amines) (Almeida et al., 2013; Kirkby et al., 2011). However, the largest cluster that was detected during all NPF events was the sulfuric acid trimer only, without any additional molecule. The trimer alone is not indicative of the full nucleation mechanism and the stabilizing compound was not identified. Larger clusters were probably not measured because of the low concentrations of the nucleating vapors, which did not produce enough clusters (the sulfuric acid trimer was already close to the detection limit of the mass spectrometer). It is not surprising 
(a)

(a) $10^{0}$

$10^{1}$

$\mathrm{dN} / \mathrm{dlog} \mathrm{Dp}\left[\mathrm{cm}^{-3}\right]$

$10^{2}$

$10^{3}$

$10^{4}$

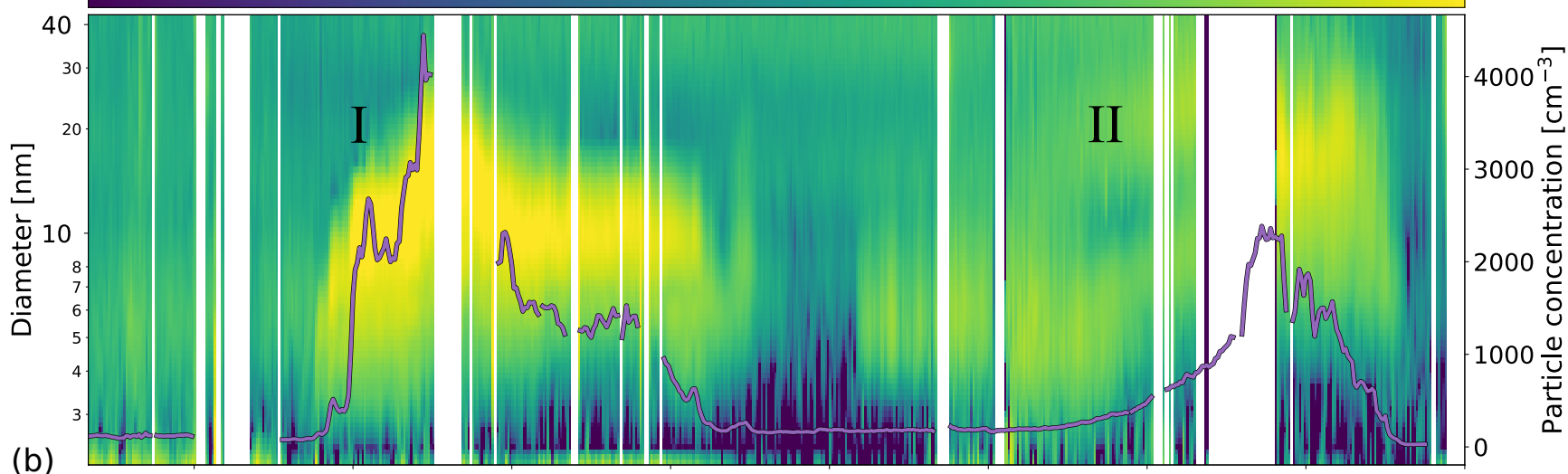

(b)

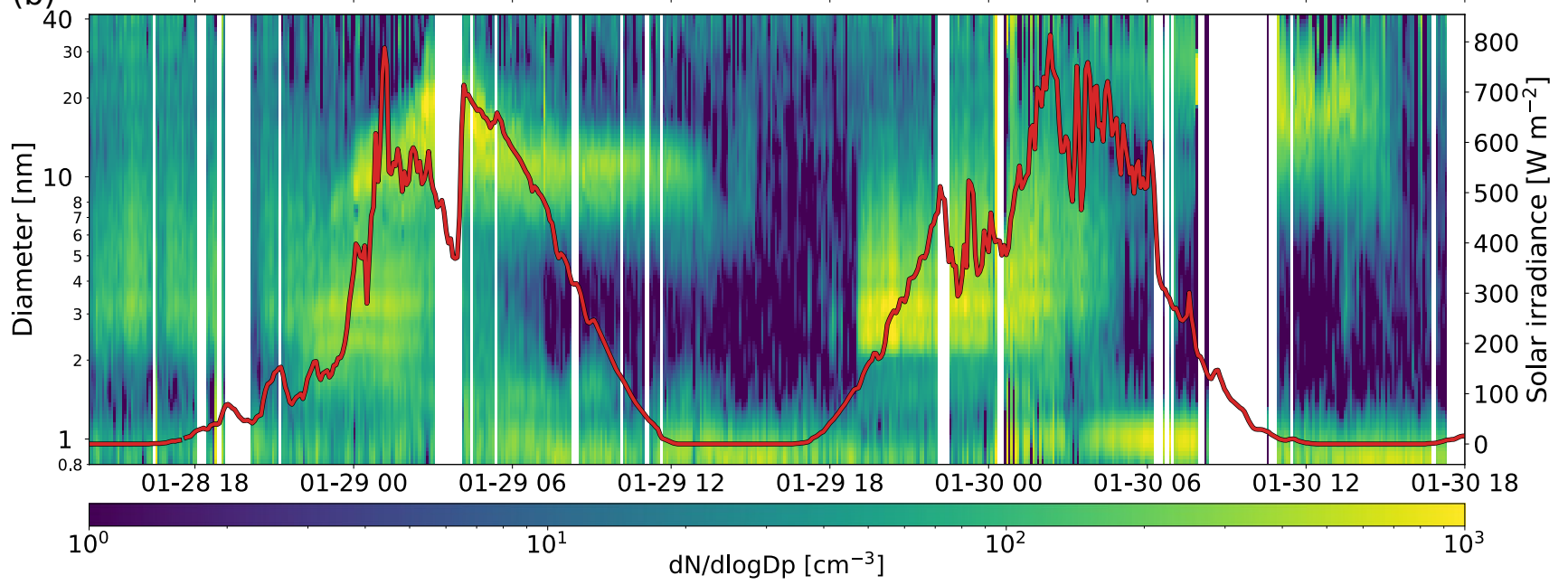

Figure 10. New particle formation events I and II, (a) total particle size distribution (2.5-42 nm) and number concentration of particles larger than $7 \mathrm{~nm}$ (right axis). (b) negatively charged ion size distribution $(0.8-42 \mathrm{~nm}$ ) and solar irradiance time series (right axis). Pollution periods were removed from the figure.

that no bases clustered with the sulfuric acid trimer were detected as these are typically found only in larger clusters with at least 4 sulfuric acid molecules (Schobesberger et al., 2015).

Figures S10 and S11 in Supporting Information S1 show the remaining 3 NPF events, which are similar to those described above. The event in Figure S11 in Supporting Information S1 is slightly different because it occurred during sunset. However, the real onset of nucleation was not detected in this case (particles were already larger than $4 \mathrm{~nm}$ ), indicating that the event started during day time and the newly formed particles were then advected to the ship location (or alternatively, the ship transited through the NPF location).

Figure 12 reports the locations of all detected NPF events and the corresponding boundary layer 5-day airmass back trajectories calculated with the Lagrangian analysis tool LAGRANTO (Sprenger \& Wernli, 2015), for additional details the reader is referred to Thurnherr et al. (2020). Events are numbered according to Figures 10 and 11, Figures S10 and S11 in Supporting Information S1. All events are characterized by a marine influence with air masses usually coming from the more productive sea ice region around Antarctica. The only exception is event $V I$, which happened closer to South America and was not influenced by any sea ice region. These results are in line with previous studies (Brean et al., 2021; Dall'Osto et al., 2017; Jokinen et al., 2018; Lachlan-Cope et al., 2020) showing that sea ice regions around Antarctica can be an important source of nucleating vapors (i.e., DMS, ammonia, alkylamines) and must be differentiated from open waters where NPF appears to occur less frequently in the boundary layer.

The two regional NPF events I and II were exceptional because of the environmental conditions encountered. In particular, the temperature and the condensation sink were low during these events with the 
(a) $10^{1}$

dN/dlog $D p\left[\mathrm{~cm}^{-3}\right]$

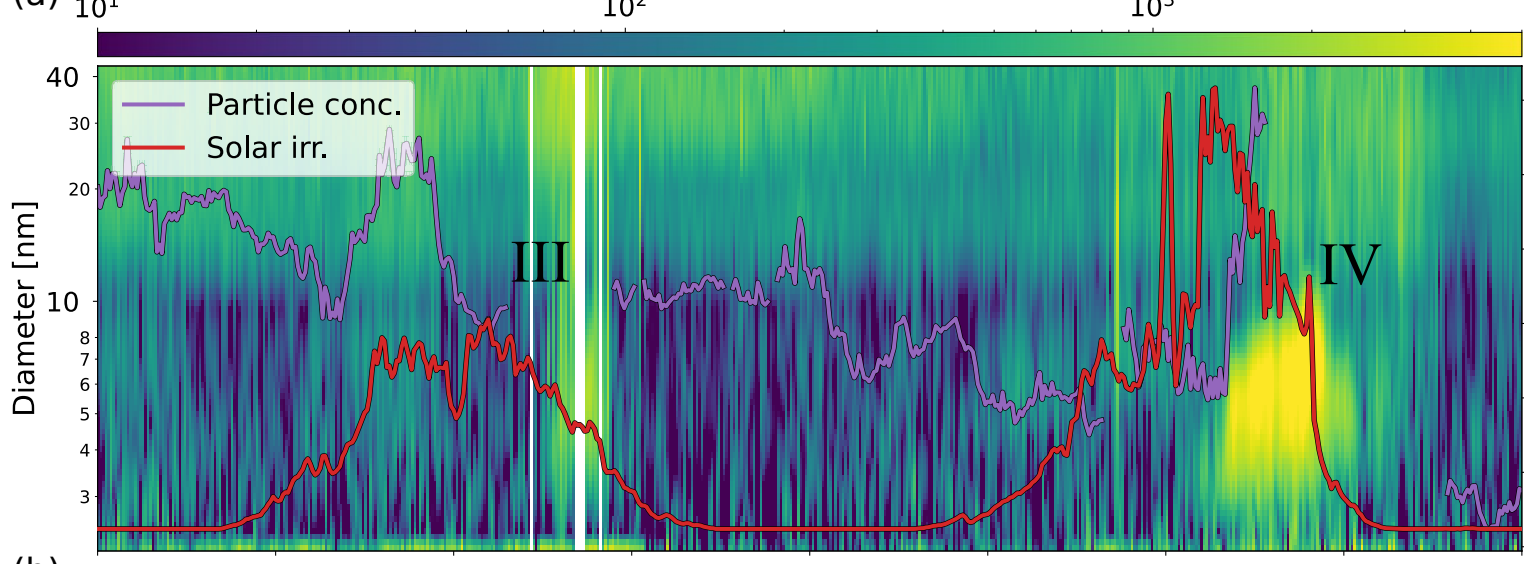

$10^{3}$

(b)

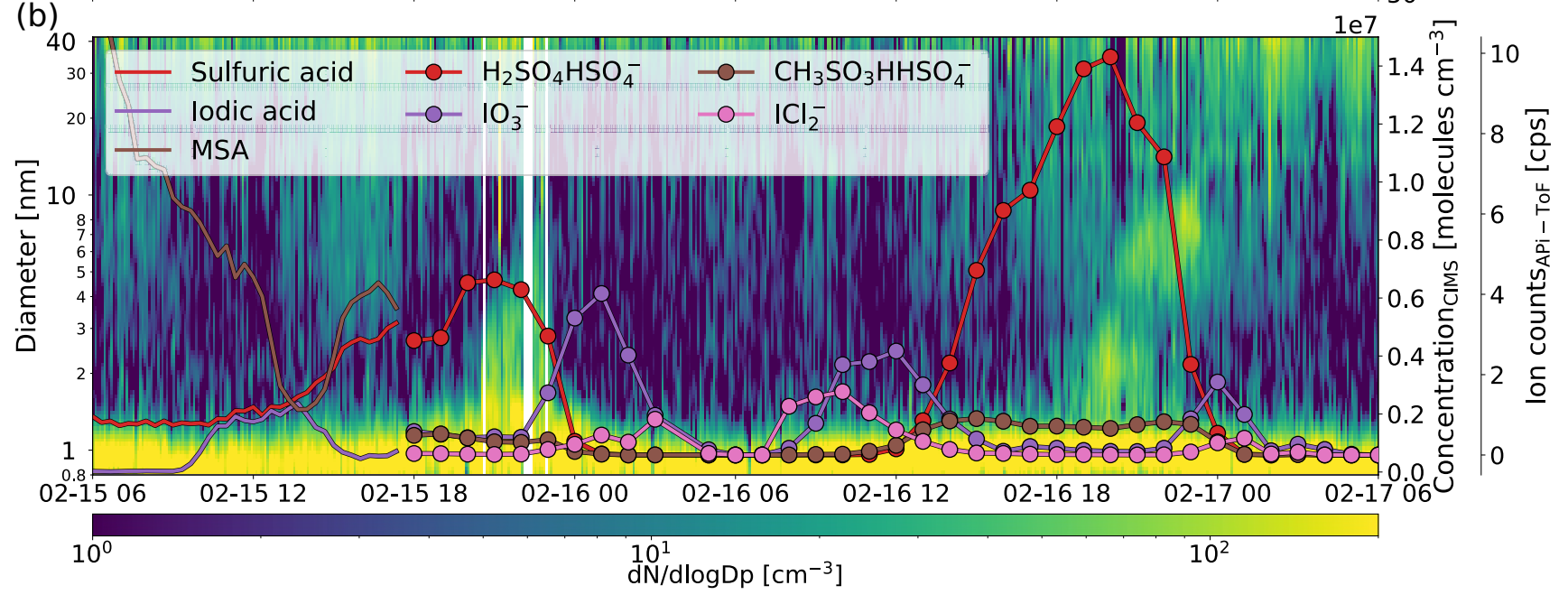

Figure 11. New particle formation events III and IV, (a) total particle size distribution $(2.5-42 \mathrm{~nm}$ ) and, on the right axis, number concentration of particles larger than $7 \mathrm{~nm}$ and solar irradiance time series. (b) negatively charged ion size distribution (0.8-42 nm), on the right axis the concentration of neutral molecules measured with the CI-APi-ToF (solid line) and the negative ions measured with the APi-ToF (round markers) are reported. Only the 4 ions with the largest signal are reported here, the sulfuric acid and methanesulfonic acid monomers are not present because of the instrument mass transmission, which was set to higher masses. Pollution periods were removed from the figure.

median temperature being within the first 5 percentiles and the median condensation sink within the first 20 percentiles for both events. At the same time, solar irradiance was above the $75^{\text {th }}$ percentile. Importantly, the combination of these 3 parameters was unique during the entire ACE expedition, which means that there were no other occurrences with similarly low temperature, condensation sink and high solar radiation at the same time. These three parameters are particularly important for NPF because they control the sulfuric acid concentration: more intense solar radiation enhances the $\mathrm{OH}$ production increasing the sulfuric acid concentration, while the condensation sink is the main sulfuric acid loss term. They also control the nucleation rates: temperature has a direct effect on the nucleating cluster stability (Kirkby et al., 2011). The exceptional combination of these three parameters probably explains why these two events were different from the rest of the campaign and also helps understanding the difference between ACE and the NPF results reported from Aboa, an Antarctic research station located about $130 \mathrm{~km}$ inland from the Southern Ocean coast (Jokinen et al., 2018). There, Jokinen et al. (2018) reported the frequent occurrence of NPF when the air mass was coming from the surrounding oceanic or sea ice region. This region should be similar in terms of emissions to the area sampled during the most southerly part of the ACE track. However, the frequency and intensity of NPF events recorded in Aboa was much higher. NPF in Aboa is driven by sulfuric acid, which was frequently higher than $10^{7}$ molecules $\mathrm{cm}^{-3}$, different from ACE where this threshold was almost never exceeded (Figure S12 in Supporting Information S1). However, this difference is unlikely driven by DMS emissions only, which are equal or higher along the ACE track than in the region of air mass 


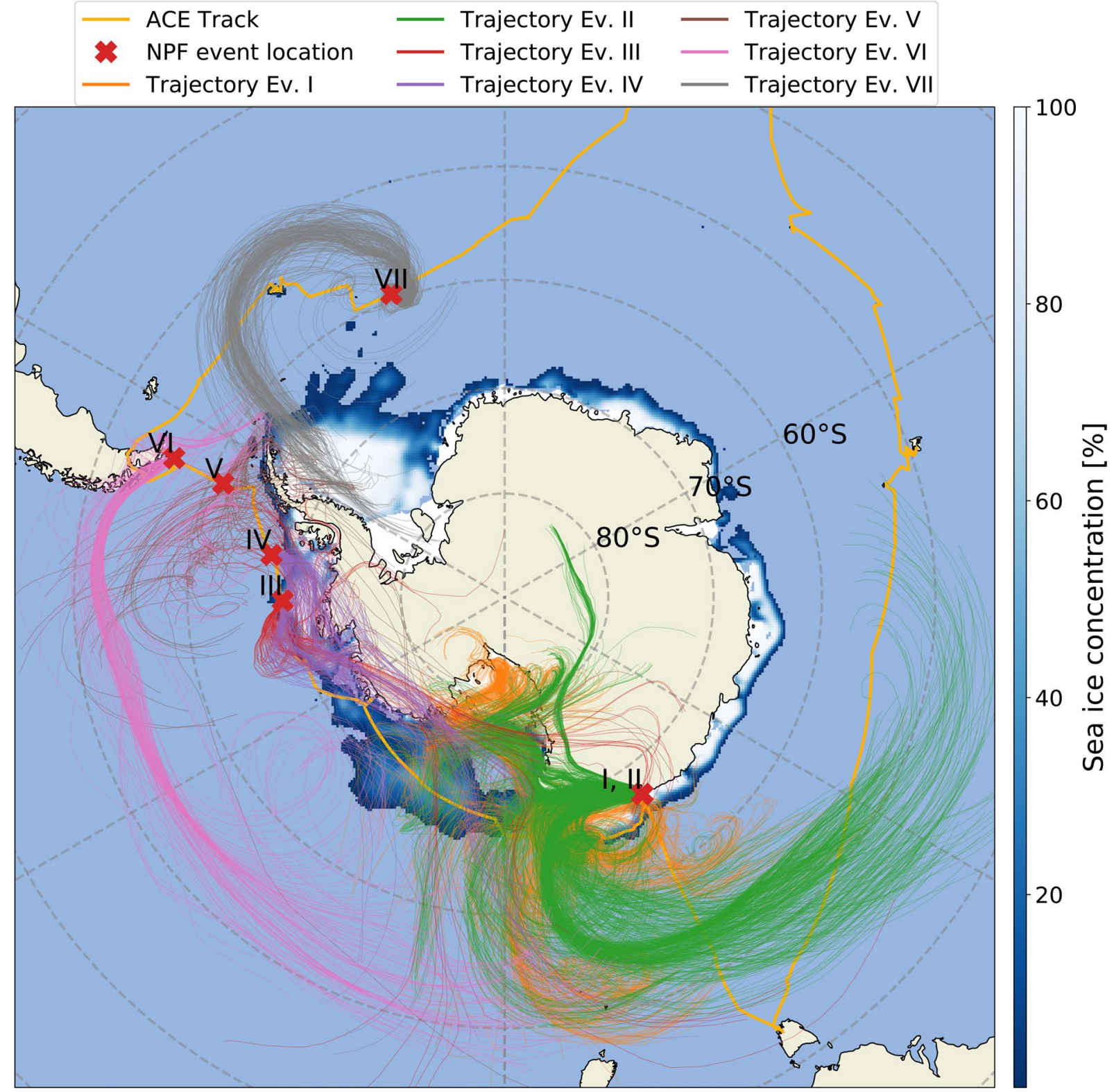

Figure 12. Map showing the Antarctic Circumnavigation Expedition track, the location of new particle formation (NPF) events and the 5-day boundary layer air mass back trajectories for each of the events. The back trajectories are shown using semi-transparent lines, different colors are associated to different NPF events. The figure also shows the sea ice concentration (fraction of covered surface) retrieved for January 2017 (Maslanik \& Stroeve, 1999).

origin for the Aboa NPF events (Lana et al., 2011; Mahajan et al., 2015). Rather, the higher sulfuric acid reported at Aboa can probably be explained by the lower condensation sink, a factor two lower on average than during ACE (Figure S13 in Supporting Information S1), and the higher SIR. Additionally, the temperature measured in Aboa was $2-5{ }^{\circ} \mathrm{C}$ lower than the minimum temperature recorded during ACE (with the exception of a single day), and this also enhances NPF. The different temperature and SIR values in Aboa are simply due to the meteorological conditions (the Antarctic continent is colder and less cloudy than the surrounding ocean (King \& Turner, 1997)), whereas the lower condensation sink can be explained by the short lifetime of the coarse mode aerosol, which is responsible for a large fraction of the condensation sink over the ocean and would be removed by the time they have reached Aboa. Another important difference is the detection of ammonia, which was frequently measured by Jokinen et al. (2018) in negative clusters with acids but never observed during ACE. A quantitative comparison of the ammonia concentration is not possible because this molecule was not measured directly during either campaign (ammonia was only detected 
as a cluster with sulfuric acid). It is possible that during the study of Jokinen et al. (2018) the ammonia concentration was on average higher compared to ACE. However, during ACE a large variety of different locations were explored, including places in close proximity to penguin colonies which are known to be strong sources of ammonia (Croft et al., 2016; Schmale et al., 2013). Therefore, it is unlikely that ammonia was the only limiting factor for NPF during ACE but it may have contributed together with the other factors described above (temperature, SIR and condensation sink).

Despite the rare occurrence of boundary layer NPF, an Aitken mode was frequently detected during ACE contributing to a large fraction of the total particle number concentration as reported in Figure S14 in Supporting Information S1. The origin of these Aitken mode particles remains unknown but it is compatible with the hypothesis from previous studies suggesting that NPF may be prevalently occurring in the free troposphere (Korhonen et al., 2008; McCoy et al., 2021; Sanchez et al., 2021; Weber et al., 1998). However, it is difficult to explain the growth of the freshly formed particles to the typical 30-50 nm Aitken mode diameter (Schmale, Baccarini, et al., 2019) considering the low concentration of condensable vapors. Investigating this topic in detail is beyond the scope of this work and should be the focus of future studies.

\section{Conclusions}

The Southern Ocean is one of the most pristine locations on Earth (Hamilton et al., 2014) and measurements in this region can be valuable to better understand the state of the atmosphere in preindustrial times and constrain the radiative forcing uncertainty in global climate models (Regayre et al., 2020). This work presents an overview of the spatial distribution of sulfuric acid, MSA and iodic acid across the Southern Ocean together with ultrafine particle and ion concentration as well as size distribution. These are all quantities that are relevant for new particle formation and growth. Obtaining a better understanding of the processes and the environmental conditions regulating their distribution can, therefore, be valuable to properly represent aerosol sources and properties in global climate models. There are studies which previously investigated trace gases (sulfuric acid and MSA) (Jefferson, Tanner, Eisele, \& Berresheim, 1998; Jefferson, Tanner, Eisele, Davis, et al., 1998), new particle formation (Dall'Osto et al., 2017; Weber et al., 1998; Weller et al., 2015) or both (Brean et al., 2021; Jokinen et al., 2018) over the Southern Ocean and coastal Antarctica. However they covered only specific geographical areas. The work presented here is the first comprehensive investigation of trace gases and new particle formation across the Southern Ocean providing a wide geographical coverage and a broader understanding of the processes involved.

Sulfuric acid vapor was characterized by a clear diurnal cycle with maxima at daytime consistent with photochemical production from $\mathrm{SO}_{2}$. The concentration was lower compared to recent measurements from coastal Antarctica (Jokinen et al., 2018), especially considering that only an upper limit was reported here due to instrumental issues. This had a direct effect on the occurrence of NPF events which were weak in terms of particle production and very sporadic. The lower sulfuric acid vapor concentration was attributed mainly to environmental reasons, such as the high condensation sink and rather low solar irradiance.

Iodic acid also exhibited a diurnal cycle with very low concentrations during night time, as expected from a molecule that is formed from the photochemically produced iodine radical. However, the iodine concentration peaked at dawn and dusk with consistently lower concentration during the central part of the day when solar radiation was stronger. This observation, which has not been reported before, could be related with the photolysis of an iodic acid precursor molecule (e.g., $\mathrm{IO}_{\text {or }} \mathrm{I}_{2} \mathrm{O}_{3}$ ) (Saiz-Lopez et al., 2012; Lewis et al., 2020). This result is important because it indicates that iodic acid could eventually reach higher concentrations when solar radiation is lower, like in spring or in autumn, if the iodine flux were comparable. As a consequence, there may be periods of the year when iodic acid may be relevant for NPF also over the Southern Ocean. Additional measurements to investigate this possibility are needed.

Finally, the gaseous MSA concentration is too low to explain the required particulate MSA values via a condensation mechanism. This suggests that MSA may be predominantly produced in the aqueous phase, as indicated already by previous modeling studies (Q. Chen et al., 2018; Hoffmann et al., 2016). Additionally, gaseous MSA does not show any diurnal cycle and tends to increase under dryer conditions, indicating that the gas phase MSA may be driven by evaporation from the particle phase. This is consistent with predictions from a thermodynamic model considering a mixture of sea spray, MSA ammonium and sulphate. Both the 
increase of MSA at lower RH and the absence of a diurnal cycle are in line with previous measurements of MSA in marine environments (Berresheim et al., 2002; Mauldin et al., 1999; Yan et al., 2019). This suggests that a more accurate treatment of MSA production and partitioning in atmospheric chemistry models is needed to improve the representation of marine sulfur compounds in the atmosphere.

Schmale, Baccarini, et al. (2019) reported a large discrepancy in the CCN number concentration around the coast of Antarctica when comparing measurements with values modeled using the Global Model of Aerosol Processes (GLOMAP) (Mann et al., 2010). This area corresponds to the strongest MSA signal detected during the entire expedition (both in the gas and in the particle phase as shown in Figure 9). The area is also known to exhibit one of the largest DMS concentrations (both in the water and in the atmosphere) in the world during summer (Lana et al., 2011; Mahajan et al., 2015). GLOMAP (as many other global climate models) only includes homogeneous production of MSA in the gas phase, whereas it does not consider condensation of this MSA nor heterogeneous production. While heterogeneous production of MSA would only contribute to the aerosol mass and not to the number concentration, the resulting shift in particle size distribution to larger diameters would increase the number of particles that can act as $\mathrm{CCN}$ at a certain supersaturation (which is strongly driven by particles size). Future studies should focus on the MSA partitioning and aqueous phase production to understand its contribution to the concentration of $\mathrm{CCN}$ and their properties.

The results obtained during ACE clearly show that discernible NPF in the boundary layer is rare across the Southern Ocean in summer and only in exceptional cases it contributes to the aerosol Aitken mode population. All detected NPF events except for one occurred over sea ice regions or were characterized by airmasses passing over these. Sulfuric acid was the main nucleating compound for the observed NPF events. A base, such as ammonia or amines, would also be required to stabilize the nucleating clusters given the low sulfuric acid concentration (Almeida et al., 2013; Kirkby et al., 2011) but no stabilizing compound was identified, probably because of the low concentration. We also found that environmental conditions, mainly temperature and the condensation sink, are critical in determining the occurrence of NPF and are likely responsible for the more frequent occurrence of this process over coastal Antarctica compared to the open Southern Ocean as reported by multiple studies (Brean et al., 2021; Clarke et al., 1998; Gras et al., 2009; Heintzenberg et al., 2004; Jimi et al., 2008; Jokinen et al., 2018; Weller et al., 2015). The low relevance of boundary layer NPF together with the frequent detection of Aitken mode aerosols is compatible with new particles being formed in the free troposphere and then transported downward as shown also by other studies (Clarke \& Kapustin, 2002; Clarke et al., 1998; Sanchez et al., 2021; Weber et al., 1998). This hypothesis cannot be confirmed with our data set because we lack information concerning the vertical distribution of aerosol particles. Future expeditions in the region should specifically address this topic, investigating aerosol sources both in the boundary layer and in the free troposphere while trying to understand their exchange processes.

\section{Data Availability Statement}

All datasets used in this study are referenced in the text (Baccarini et al., 2019a, 2019b, 2021a, 2021b; Landwehr et al., 2019; Tatzelt et al., 2020; Thurnherr et al., 2020; Schmale et al., 2019a, 2019b) and publically available on Zenodo (https://zenodo.org/). Concentration of gaseous sulfuric acid measured over the Southern Ocean in the austral summer of 2016/2017, during the Antarctic Circumnavigation Expedition (ACE) (https://doi.org/10.5281/zenodo.3265832). Concentration of gaseous methanesulfonic acid measured over the Southern Ocean in the austral summer of 2016/2017, during the Antarctic Circumnavigation Expedition (ACE) (https://doi.org/10.5281/zenodo.2636771). Concentration of gaseous iodic acid measured over the Southern Ocean in the austral summer of 2016/2017, during the Antarctic Circumnavigation Expedition (ACE) (https://doi.org/10.5281/zenodo.5176217). Size distribution of neutral and charged particles smaller than $42 \mathrm{~nm}$ measured over the Southern Ocean in the austral summer of 2016/2017, during the Antarctic Circumnavigation Expedition (ACE) (https://doi.org/10.5281/zenodo.5180560). Sub-micron aerosol particle size distribution collected in the Southern Ocean in the austral summer of 2016/2017, during the Antarctic Circumnavigation Expedition (https://doi.org/10.5281/zenodo.2636700). Coarse mode aerosol particle size distribution collected in the Southern Ocean in the austral summer of 2016/2017, during the Antarctic Circumnavigation Expedition (https://doi.org/10.5281/zenodo.2636709). Ionic composition of particulate matter (PM10) from high-volume sampling over the Southern Ocean during the austral summer 
of 2016/2017 on board the Antarctic Circumnavigation Expedition (ACE) (https://doi.org/10.5281/zenodo.3922147). Quality-checked meteorological data from the Southern Ocean collected during the Antarctic Circumnavigation Expedition from December 2016 to April 2017 (https://doi.org/10.5281/zenodo.3379590). 10-day backward trajectories from ECMWF analysis data along the ship track of the Antarctic Circumnavigation Expedition in austral summer 2016/2017 (https://doi.org/10.5281/zenodo.4031704).

\section{Acknowledgments}

The authors thank Christian Tatzelt for providing the $\mathrm{PM}_{10}$ filter data, and Markus Hartmann and André Welti for operating instruments on leg 1 and 3 , respectively. The authors are also grateful to Tuija Jokinen and Mikko Sipilä for providing data from the Aboa station. The Antarctic Circumnavigation Expedition was funded by the Swiss Polar Institute and Ferring Pharmaceuticals. A. Baccarini was supported by the SNSF Grant No. 200021_169090. J. Schmale holds the Ingvar Kamprad Chair for Extreme Environments Research. Open access funding enabled and organized by Projekt DEAL.

\section{References}

Almeida, J., Schobesberger, S., Kürten, A., Ortega, I. K., Kupiainen-Määttä, O., Praplan, A. P., \& Kirkby, J. (2013). Molecular understanding of sulphuric acid-amine particle nucleation in the atmosphere. Nature, 502(7471), 359-363. https://doi.org/10.1038/nature12663

Altieri, K. E., Spence, K. A. M., \& Smith, S. (2021). Air-sea ammonia fluxes calculated from high-resolution summertime observations across the Atlantic Southern Ocean. Geophysical Research Letters, 48, 1-9. https://doi.org/10.1029/2020gl091963

Ammann, M., Cox, R. A., Crowley, J. N., Jenkin, M. E., Mellouki, A., Rossi, M. J., et al. (2013). Evaluated kinetic and photochemical data for atmospheric chemistry: Volume VI - Heterogeneous reactions with liquid substrates. Atmospheric Chemistry and Physics, 13(16), 8045-8228. https://doi.org/10.5194/acp-13-8045-2013

Baccarini, A., Karlsson, L., Dommen, J., Duplessis, P., Vüllers, J., Brooks, I. M., et al. (2020). Frequent new particle formation over the high Arctic pack ice by enhanced iodine emissions. Nature Communications, 11(1) 4924. https://doi.org/10.1038/s41467-020-18551-0

Baccarini, A., Schmale, J., Henning, S., Tummon, F., Hartmann, M., Welti, A., et al. (2019a). Concentration of gaseous methanesulfonic acid measured over the Southern Ocean in the austral summer of 2016/2017, during the Antarctic Circumnavigation Expedition (ACE). Zenodo. Retrieved from https://zenodo.org/record/2636771

Baccarini, A., Schmale, J., Henning, S., Tummon, F., Hartmann, M., Welti, A., et al. (2019b). Concentration of gaseous sulfuric acid measured over the Southern Ocean in the austral summer of 2016/2017, during the Antarctic Circumnavigation Expedition (ACE). Zenodo. Retrieved from https://zenodo.org/record/3265832

Baccarini, A., Schmale, J., Henning, S., Tummon, F., Hartmann, M., Welti, A., et al. (2021a). Concentration of gaseous iodic acid measured over the Southern Ocean in the austral summer of 2016/2017, during the Antarctic Circumnavigation Expedition (ACE). Zenodo. https:// doi.org/10.5281/zenodo.5176217

Baccarini, A., Schmale, J., Henning, S., Tummon, F., Hartmann, M., Welti, A., et al. (2021b). Size distribution of neutral and charged particles smaller than $42 \mathrm{~nm}$ measured over the Southern Ocean in the austral summer of 2016/2017, during the Antarctic Circumnavigation Expedition (ACE). Zenodo. https://doi.org/10.5281/zenodo.5180560

Barbaro, E., Padoan, S., Kirchgeorg, T., Zangrando, R., Toscano, G., Barbante, C., \& Gambaro, A. (2017). Particle size distribution of inorganic and organic ions in coastal and inland Antarctic aerosol. Environmental Science and Pollution Research, 24(3), 2724-2733. https:// doi.org/10.1007/s11356-016-8042-x

Barnes, I., Hjorth, J., \& Mihalapoulos, N. (2006). Dimethyl sulfide and dimethyl sulfoxide and their oxidation in the atmosphere. Chemical Reviews, 106(3), 940-975. https://doi.org/10.1021/cr020529

Beck, L. J., Sarnela, N., Junninen, H., Hoppe, C. J. M., Garmash, O., Bianchi, F., et al. (2021). Differing mechanisms of new particle formation at two Arctic sites. Geophysical Research Letters, 48(4), 1-11. https://doi.org/10.1029/2020GL091334

Berg, O. H., Swietlicki, E., \& Krejci, R. (1998). Hygroscopic growth of aerosol particles in the marine boundary layer over the Pacific and Southern Oceans during the First Aerosol Characterization Experiment (ACE 1). Journal of Geophysical Research, 103(D13), 1653516545. https://doi.org/10.1029/97JD02851

Berresheim, H., Adam, M., Monahan, C., O'Dowd, C., Plane, J. M. C., Bohn, B., \& Rohrer, F. (2014). Missing $\mathrm{SO}_{2}$ oxidant in the coastal atmosphere? - Observations from high-resolution measurements of $\mathrm{OH}$ and atmospheric sulfur compounds. Atmospheric Chemistry and Physics, 14(22), 12209-12223. https://doi.org/10.5194/acp-14-12209-2014

Berresheim, H., Elste, T., Tremmel, H. G., Allen, A. G., Hansson, H. C., Rosman, K., et al. (2002). Gas-aerosol relationships of $\mathrm{H}_{2} \mathrm{SO}_{4}$, MSA, and $\mathrm{OH}$ : Observations in the coastal marine boundary layer at Mace Head, Ireland. Journal of Geophysical Research, 107(D19), 8100. https://doi.org/10.1029/2000JD000229

Brean, J., Dall'Osto, M., Simó, R., Shi, Z., Beddows, D. C. S., \& Harrison, R. M. (2021). Open ocean and coastal new particle formation from sulfuric acid and amines around the Antarctic Peninsula. Nature Geoscience, 14(6), 383-388. https://doi.org/10.1038/s41561-021-00751-y

Carslaw, K. S., Gordon, H., Hamilton, D. S., Johnson, J. S., Regayre, L. A., Yoshioka, M., \& Pringle, K. J. (2017). Aerosols in the Pre-industrial Atmosphere. Current Climate Change Reports, 3(1), 1-15. https://doi.org/10.1007/s40641-017-0061-2

Carslaw, K. S., Lee, L. A., Reddington, C. L., Pringle, K. J., Rap, A., Forster, P. M., et al. (2013). Large contribution of natural aerosols to uncertainty in indirect forcing. Nature, 503(7474), 67-71. https://doi.org/10.1038/nature12674

Chambers, S. D., Preunkert, S., Weller, R., Hong, S.-B., Humphries, R. S., Tositti, L., et al. (2018). Characterizing Atmospheric transport pathways to Antarctica and the remote Southern Ocean using Radon-222. Frontiers of Earth Science, 6. https://doi.org/10.3389/ feart.2018.00190

Chen, Q., Sherwen, T., Evans, M., \& Alexander, B. (2018). DMS oxidation and sulfur aerosol formation in the marine troposphere: A focus on reactive halogen and multiphase chemistry. Atmospheric Chemistry and Physics, 18(18), 13617-13637. https://doi.org/10.5194/ acp-18-13617-2018

Chen, X., Virkkula, A., Kerminen, V.-M., Manninen, H. E., Busetto, M., Lanconelli, C., et al. (2017). Features in air ions measured by an air ion spectrometer (AIS) at Dome C. Atmospheric Chemistry and Physics, 17(22), 13783-13800. https://doi.org/10.5194/acp-17-13783-2017

Clarke, A. D., \& Kapustin, V. N. (2002). A pacific aerosol survey. Part I: A decade of data on particle production, transport, evolution, and mixing in the troposphere. Journal of the Atmospheric Sciences, 59(3), 363-382. https://doi.org/10.1175/1520-0469(2002)059<0363:AP ASPI $>2.0 . \mathrm{CO} ; 2$

Clarke, A. D., Varner, J. L., Eisele, F., Mauldin, R. L., Tanner, D., \& Litchy, M. (1998). Particle production in the remote marine atmosphere: Cloud outflow and subsidence during ACE 1. Journal of Geophysical Research, 103(D13), 16397-16409. https://doi. org/10.1029/97JD02987

Clegg, S. L., Brimblecombe, P., \& Wexler, A. S. (1998). Thermodynamic Model of the System $\mathrm{H}^{+}-\mathrm{NH}_{4}^{+}-\mathrm{Na}^{+}-\mathrm{SO}_{4}^{2-}-\mathrm{NO}_{3}^{-}-\mathrm{Cl}^{-}-\mathrm{H}_{2} \mathrm{O}$ at 298.15 K. The Journal of Physical Chemistry A, 102(12), 2155-2171. https://doi.org/10.1021/jp973043j

Collins, D. B., Bertram, T. H., Sultana, C. M., Lee, C., Axson, J. L., \& Prather, K. A. (2016). Phytoplankton blooms weakly influence the cloud forming ability of sea spray aerosol. Geophysical Research Letters, 43(18), 9975-9983. https://doi.org/10.1002/2016GL069922 
Croft, B., Wentworth, G. R., Martin, R. V., Leaitch, W. R., Murphy, J. G., Murphy, B. N., et al. (2016). Contribution of Arctic seabird-colony ammonia to atmospheric particles and cloud-albedo radiative effect. Nature Communications, 7(1), 1-10. https://doi.org/10.1038/ ncomms 13444

Dall'Osto, M., Airs, R. L., Beale, R., Cree, C., Fitzsimons, M. F., Beddows, D., et al. (2019). Simultaneous detection of alkylamines in the surface ocean and atmosphere of the Antarctic sympagic environment. ACS Earth and Space Chemistry, 3(5), 854-862. https://doi. org/10.1021/acsearthspacechem.9b00028

Dall'Osto, M., Ovadnevaite, J., Paglione, M., Beddows, D. C., Ceburnis, D., Cree, C., et al. (2017). Antarctic sea ice region as a source of biogenic organic nitrogen in aerosols. Scientific Reports, 7(1), 6047. https://doi.org/10.1038/s41598-017-06188-x

Dal Maso, M., Kulmala, M., Lehtinen, K. E., Mäkelä, J., Aalto, P., \& O'Dowd, C. (2002). Condensation and coagulation sinks and formation of nucleation mode particles in coastal and boreal forest boundary layers. Journal of Geophysical Research, 107(D19), PAR 2-1-PAR 2-10. https://doi.org/10.1029/2001JD001053

Davis, D., Chen, G., Bandy, A., Thornton, D., Eisele, F., Mauldin, L., et al. (1999). Dimethyl sulfide oxidation in the equatorial Pacific: Comparison of model simulations with field observations for DMS, $\mathrm{SO}_{2}, \mathrm{H}_{2} \mathrm{SO}_{4}(\mathrm{~g}), \mathrm{MSA}(\mathrm{g})$, MS and NSS. Journal of Geophysical Research: Atmospheres, 104(D5), 5765-5784. https://doi.org/10.1029/1998JD100002

Davis, D., Chen, G., Kasibhatla, P., Jefferson, A., Tanner, D., Eisele, F., et al. (1998). DMS oxidation in the Antarctic marine boundary layer: Comparison of model simulations and held observations of DMS, DMSO, DMSO ${ }_{2}, \mathrm{H}_{2} \mathrm{SO}_{4}(\mathrm{~g})$, MSA(g), and MSA(p). Journal of Geophysical Research: Atmospheres, 103(D1), 1657-1678. https://doi.org/10.1029/97JD03452

De Bruyn, W. J., Shorter, J. A., Davidovits, P., Worsnop, D. R., Zahniser, M. S., \& Kolb, C. E. (1994). Uptake of gas phase sulfur species methanesulfonic acid, dimethylsulfoxide, and dimethyl sulfone by aqueous surfaces. Journal of Geophysical Research, 99(D8), 16927. 16927-16932. https://doi.org/10.1029/94JD00684

Decesari, S., Paglione, M., Rinaldi, M., Dall'Osto, M., Simó, R., Zanca, N., et al. (2020). Shipborne measurements of Antarctic submicron organic aerosols: An NMR perspective linking multiple sources and bioregions. Atmospheric Chemistry and Physics, 20 (7), $4193-4207$. https://doi.org/10.5194/acp-20-4193-2020

Fossum, K. N., Ovadnevaite, J., Ceburnis, D., Dall'Osto, M., Marullo, S., Bellacicco, M., et al. (2018). Summertime primary and secondary contributions to Southern Ocean cloud condensation nuclei. Scientific Reports, 8(1), 13844. https://doi.org/10.1038/s41598-018-32047-4

Frey, M. M., Norris, S. J., Brooks, I. M., Anderson, P. S., Nishimura, K., Yang, X., et al. (2020). First direct observation of sea salt aerosol production from blowing snow above sea ice. Atmospheric Chemistry and Physics, 20(4), 2549-2578. https://doi.org/10.5194/ acp-20-2549-2020

Friese, E., \& Ebel, A. (2010). Temperature Dependent Thermodynamic Model of the System H+-NH4+-Na+-SO42--NO3--Cl-H2O. The Journal of Physical Chemistry A, 114(43), 11595-11631. https://doi.org/10.1021/jp101041j

Gómez Martín, J. C., Lewis, T. R., Blitz, M. A., Plane, J. M. C., Kumar, M., Francisco, J. S., \& Saiz-Lopez, A. (2020). A gas-to-particle conversion mechanism helps to explain atmospheric particle formation through clustering of iodine oxides. Nature Communications, 11(1), 4521. https://doi.org/10.1038/s41467-020-18252-8

Gordon, H., Kirkby, J., Baltensperger, U., Bianchi, F., Breitenlechner, M., Curtius, J., et al. (2017). Causes and importance of new particle formation in the present-day and preindustrial atmospheres. Journal of Geophysical Research: Atmospheres, 122(16), 8739-8760. https:// doi.org/10.1002/2017jd026844

Gras, J. L., Jimi, S. I., Siems, S. T., \& Krummel, P. B. (2009). Postfrontal nanoparticles at Cape Grim: Observations. Environmental Chemistry, 6(6), 508-514. https://doi.org/10.1071/EN09075

Hamilton, D. S., Lee, L. A., Pringle, K. J., Reddington, C. L., Spracklen, D. V., \& Carslaw, K. S. (2014). Occurrence of pristine aerosol environments on a polluted planet. Proceedings of the National Academy of Sciences, 111(52), 18466-18471. https://doi.org/10.1073/ pnas. 1415440111

Hanson, D. R. (2005). Mass accommodation of $\mathrm{H}_{2} \mathrm{SO}_{4}$ and $\mathrm{CH}_{3} \mathrm{SO}_{3} \mathrm{H}$ on water-sulfuric acid solutions from 6\% to $97 \%$ RH. The Journal of Physical Chemistry A, 109(31), 6919-6927. https://doi.org/10.1021/jp0510443

He, X.-C., Tham, Y. J., Dada, L., Wang, M., Finkenzeller, H., Stolzenburg, D., et al. (2021). Role of iodine oxoacids in atmospheric aerosol nucleation. Science, 371(6529), 589-595. https://doi.org/10.1126/science.abe0298

Heintzenberg, J., Birmili, W., Wiedensohler, A., Nowak, A., \& Tuch, T. (2004). Structure, variability and persistence of the submicrometre marine aerosol. Tellus B: Chemical and Physical Meteorology, 56(4), 357-367. https://doi.org/10.3402/tellusb.v56i4.16450

Hintze, J. L., \& Nelson, R. D. (1998). Violin plots: A box plot-density trace synergism. The American Statistician, 52(2), 181-184. https:// doi.org/10.1080/00031305.1998.10480559

Hodshire, A. L., Campuzano-Jost, P., Kodros, J. K., Croft, B., Nault, B. A., Schroder, J. C., et al. (2019). The potential role of methanesulfonic acid (MSA) in aerosol formation and growth and the associated radiative forcings. Atmospheric Chemistry and Physics, 19(5), 3137-3160. https://doi.org/10.5194/acp-19-3137-2019

Hoffmann, E. H., Tilgner, A., Schrödner, R., Bräuer, P., Wolke, R., \& Herrmann, H. (2016). An advanced modeling study on the impacts and atmospheric implications of multiphase dimethyl sulfide chemistry. Proceedings of the National Academy of Sciences of the United States of America, 113(42), 11776-11781. https://doi.org/10.1073/pnas.1606320113

Humphries, R. S., Schofield, R., Keywood, M. D., Ward, J., Pierce, J. R., Gionfriddo, C. M., et al. (2015). Boundary layer new particle formation over East Antarctic sea ice-possible Hg-driven nucleation? Atmospheric Chemistry and Physics, 15(23), 13339-13364. https://doi. org/10.5194/acp-15-13339-2015

Jang, E., Park, K.-T., Yoon, Y. J., Kim, T.-W., Hong, S.-B., Becagli, S., et al. (2019). New particle formation events observed at the King Sejong Station, Antarctic Peninsula - Part 2: Link with the oceanic biological activities. Atmospheric Chemistry and Physics, 19(11), 7595-7608. https://doi.org/10.5194/acp-19-7595-2019

Järvinen, E., Virkkula, A., Nieminen, T., Aalto, P. P., Asmi, E., Lanconelli, C., et al. (2013). Seasonal cycle and modal structure of particle number size distribution at Dome C, Antarctica. Atmospheric Chemistry and Physics, 13(15), 7473-7487. https://doi.org/10.5194/ acp-13-7473-2013

Jefferson, A., Tanner, D. J., Eisele, F. L., \& Berresheim, H. (1998). Sources and sinks of $\mathrm{H}_{2} \mathrm{SO}_{4}$ in the remote Antarctic marine boundary layer. Journal of Geophysical Research, 103(D1), 1639-1645. https://doi.org/10.1029/97JD01212

Jefferson, A., Tanner, D. J., Eisele, F. L., Davis, D. D., Chen, G., Crawford, J., et al. (1998). OH photochemistry and methane sulfonic acid formation in the coastal Antarctic boundary layer. Journal of Geophysical Research, 103(D1), 1647-1656. https://doi.org/10.1029/97JD02376

Jimi, S. I., Siems, S. T., McGregor, J. L., Gras, J. L., \& Katzfey, J. J. (2008). An investigation into the origin of aerosol nucleation events observed in the Southern Ocean boundary layer. Australian Meteorological Magazine, 57(2), 85-93. http://hdl.handle.net/102.100.100/ 118569 ? index $=1$ 
Jokinen, T., Sipilä, M., Junninen, H., Ehn, M., Lönn, G., Hakala, J., et al. (2012). Atmospheric sulphuric acid and neutral cluster measurements using CI-APi-TOF. Atmospheric Chemistry and Physics, 12(9), 4117-4125. https://doi.org/10.5194/acp-12-4117-2012

Jokinen, T., Sipilä, M., Kontkanen, J., Vakkari, V., Tisler, P., Duplissy, E., et al. (2018). Ion-induced sulfuric acid-ammonia nucleation drives particle formation in coastal Antarctica. Science Advances, 4(11). https://doi.org/10.1126/sciadv.aat9744

Jourdain, B., \& Legrand, M. (2002). Year-round records of bulk and size-segregated aerosol composition and and levels in the Dumont d'Urville (coastal Antarctica) atmosphere: Implications for sea-salt aerosol fractionation in the winter and summer. Journal of Geophysical Research, 107(D22), ACH 20-1-ACH 20-13. https://doi.org/10.1029/2002JD002471

Junninen, H., Ehn, M., PetäjäLuosujärvi, L., Kotiaho, T., Kostiainen, R., et al. (2010). A high-resolution mass spectrometer to measure atmospheric ion composition. Atmospheric Measurement Techniques, 3(4), 1039-1053. https://doi.org/10.5194/amt-3-1039-2010

Katoshevski, D., Nenes, A., \& Seinfeld, J. H. (1999). A study of processes that govern the maintenance of aerosols in the marine boundary layer. Journal of Aerosol Science, 30(4), 503-532. https://doi.org/10.1016/S0021-8502(98)00740-X

Kim, J., Yoon, Y. J., Gim, Y., Choi, J. H., Kang, H. J., Park, K.-T., \& Lee, B. Y. (2019). New particle formation events observed at King Sejong Station, Antarctic Peninsula - Part 1: Physical characteristics and contribution to cloud condensation nuclei. Atmospheric Chemistry and Physics, 19(11), 7583-7594. https://doi.org/10.5194/acp-19-7583-2019

King, J. C., \& Turner, J. (1997). Antarctic Meteorology and Climatology. Cambridge University Press. https://doi.org/10.1017/ CBO9780511524967

Kirkby, J., Curtius, J., Almeida, J., Dunne, E., Duplissy, J., Ehrhart, S., et al. (2011). Role of sulphuric acid, ammonia and galactic cosmic rays in atmospheric aerosol nucleation. Nature, 476(7361), 429-435. https://doi.org/10.1038/nature10343

Korhonen, H., Carslaw, K. S., Spracklen, D. V., Riley, D. A., \& Ström, J. (2008). A global model study of processes controlling aerosol size distributions in the Arctic spring and summer. Journal of Geophysical Research, 113(D8), 1-20. https://doi.org/10.1029/2007JD009114

Kulkarni, P., Baron, P. A., \& Willeke, K. (2011). Aerosol measurement: Principles, techniques, and applications. John Wiley \& Sons. https:// doi.org/10.1002/9781118001684

Kürten, A., Rondo, L., Ehrhart, S., \& Curtius, J. (2012). Calibration of a chemical ionization mass spectrometer for the measurement of gaseous sulfuric acid. Journal of Physical Chemistry A, 116(24), 6375-6386. https://doi.org/10.1021/jp212123n

Lachlan-Cope, T., Beddows, D. C. S., Brough, N., Jones, A. E., Harrison, R. M., Lupi, A., et al. (2020). On the annual variability of Antarctic aerosol size distributions at Halley Research Station. Atmospheric Chemistry and Physics, 20(7), 4461-4476. https://doi.org/10.5194/ acp-20-4461-2020

Lana, A., Bell, T. G., Simó, R., Vallina, S. M., Ballabrera-Poy, J., Kettle, A. J., et al. (2011). An updated climatology of surface dimethlysulfide concentrations and emission fluxes in the global ocean. Global Biogeochemical Cycles, 25(1), 1-17. https://doi.org/10.1029/2010gb003850

Landwehr, S., Thomas, J., Gorodetskaya, I., Thurnherr, I., Robinson, C., \& Schmale, J. (2019). Quality-checked meteorological data from the Southern Ocean collected during the Antarctic Circumnavigation Expedition from December 2016 to April 2017. Zenodo. https://doi. org/10.5281/zenodo.3379590

Landwehr, S., Volpi, M., Alexander Haumann, F., Robinson, C. M., Thurnherr, I., Ferracci, V., \& Schmale, J. (2021). Biogeochemistry and physics of the southern ocean-atmosphere system explored with data science. Earth System Dynamics Discussions. https://doi. org/10.5194/esd-2021-16

Legrand, M., Ducroz, F., Wagenbach, D., Mulvaney, R., \& Hall, J. (1998). Ammonium in coastal Antarctic aerosol and snow: Role of polar ocean and penguin emissions. Journal of Geophysical Research, 103(D9), 11043-11056. https://doi.org/10.1029/97JD01976

Lewis, T. R., Gómez Martín, J. C., Blitz, M. A., Cuevas, C. A., Plane, J. M. C., \& Saiz-Lopez, A. (2020). Determination of the absorption cross sections of higher-order iodine oxides at 355 and $532 \mathrm{~nm}$. Atmospheric Chemistry and Physics, 20(18), 10865-10887. https://doi. org/10.5194/acp-20-10865-2020

Long, M. S., Keene, W. C., Kieber, D. J., Frossard, A. A., Russell, L. M., Maben, J. R., et al. (2014). Light-enhanced primary marine aerosol production from biologically productive seawater. Geophysical Research Letters, 41(7), 2661-2670. https://doi.org/10.1002/2014gl059436

Lucas, D. D. (2002). Mechanistic studies of dimethylsulfide oxidation products using an observationally constrained model. Journal of Geophysical Research, 107(D14), ACH 12-1-ACH 12-26. https://doi.org/10.1029/2001JD000843

Mahajan, A. S., Fadnavis, S., Thomas, M. A., Pozzoli, L., Gupta, S., Royer, S.-J., et al. (2015). Quantifying the impacts of an updated global dimethyl sulfide climatology on cloud microphysics and aerosol radiative forcing. Journal of Geophysical Research: Atmospheres, 120(6), 2524-2536. https://doi.org/10.1002/2014JD022687

Mann, G. W., Carslaw, K. S., Spracklen, D. V., Ridley, D. A., Manktelow, P. T., Chipperfield, M. P., \& Johnson, C. E. (2010). Description and evaluation of GLOMAP-mode: A modal global aerosol microphysics model for the UKCA composition-climate model. Geoscientific Model Development, 3(2), 519-551. https://doi.org/10.5194/gmd-3-519-2010

Manninen, H. E., Nieminen, T., Asmi, E., Gagné, S., Häkkinen, S., Lehtipalo, K., et al. (2010). EUCAARI ion spectrometer measurements at 12 European sites-analysis of new particle formation events. Atmospheric Chemistry and Physics, 10(16), 7907-7927. https://doi. org/10.5194/acp-10-7907-2010

MÅrtensson, M., Tunved, P., Korhonen, H., \& Nilsson, D. (2010). The role of sea-salt emissions in controlling the marine Aitken and accumulation mode aerosol: A model study. Tellus B: Chemical and Physical Meteorology, 62(4), 259-279. https://doi. org $/ 10.1111 / \mathrm{j} .1600-0889.2010 .00465 . x$

Maslanik, J., \& Stroeve, J. (1999). Near-real-time DMSP SSMIS daily polar gridded sea ice concentrations, version 1. Boulder, Colorado USA: NASA National Snow and Ice Data Center Distributed. Active Archive Center. https://doi.org/10.5067/U8C09DWVX9LM

Mauldin, R. L., Cantrell, C. A., Zondlo, M., Kosciuch, E., Eisele, F. L., Chen, G., et al. (2003). Highlights of OH, $\mathrm{H}_{2} \mathrm{SO}_{4}$ and methane sulfonic acid measurements made aboard the NASA P-3B during transport and chemical evolution over the Pacific. Journal of Geophysical Research, 108(20), 1-13. https://doi.org/10.1029/2003jd003410

Mauldin, R. L., Tanner, D. J., Heath, J. A., Huebert, B. J., \& Eisele, F. L. (1999). Observations of $\mathrm{H}_{2} \mathrm{SO}_{4}$ and MSA during PEM-Tropics-A. Journal of Geophysical Research, 104(D5), 5801-5816. https://doi.org/10.1029/98JD02612

McCoy, I. L., Bretherton, C. S., Wood, R., Twohy, C. H., Gettelman, A., Bardeen, C. G., \& Toohey, D. W. (2021). Influences of recent particle formation on southern ocean aerosol variability and low cloud properties. Journal of Geophysical Research: Atmospheres, 126(8), 1-39. https://doi.org/10.1029/2020jd033529

McCoy, I. L., McCoy, D. T., Wood, R., Regayre, L., Watson-Parris, D., Grosvenor, D. P., et al. (2020). The hemispheric contrast in cloud microphysical properties constrains aerosol forcing. Proceedings of the National Academy of Sciences, 117(32), 18998-19006. https://doi. org/10.1073/pnas.1922502117

Mirme, S., \& Mirme, A. (2013). The mathematical principles and design of the NAIS - A spectrometer for the measurement of cluster ion and nanometer aerosol size distributions. Atmospheric Measurement Techniques, 6(4), 1061-1071. https://doi.org/10.5194/ amt-6-1061-2013 
Modini, R. L., Frossard, A. A., Ahlm, L., Russell, L. M., Corrigan, C. E., Roberts, G. C., et al. (2015). Primary marine aerosol-cloud interactions off the coast of California. Journal of Geophysical Research: Atmospheres, 120(9), 4282-4303. https://doi.org/10.1002/2014jd022963

Nowlin, W. D., \& Klinck, J. M. (1986). The physics of the Antarctic Circumpolar Current. Reviews of Geophysics, 24(3), 469-491. https:// doi.org/10.1029/RG024i003p00469

Ovaska, T., Niemi, S., Sirviö, K., Nilsson, O., Portin, K., \& Asplund, T. (2019). Effects of alternative marine diesel fuels on the exhaust particle size distributions of an off-road diesel engine. Applied Thermal Engineering, 150, 1168-1176. https://doi.org/10.1016/j. applthermaleng.2019.01.090

Paulsen, D., Dommen, J., Kalberer, M., Prévôt, A. S. H., Richter, R., Sax, M., \& Baltensperger, U. (2005). Secondary Organic Aerosol Formation by Irradiation of 1, 3, 5-Trimethylbenzene- $\mathrm{NO}_{\mathrm{x}}-\mathrm{H}_{2} \mathrm{O}$ in a New Reaction Chamber for Atmospheric Chemistry and Physics. Environmental Science \& Technology, 39(8), 2668-2678. https://doi.org/10.1021/es0489137

Pirjola, L., O'Dowd, C. D., Brooks, I. M., \& Kulmala, M. (2000). Can new particle formation occur in the clean marine boundary layer? Journal of Geophysical Research, 105(D21), 26531-26546. https://doi.org/10.1029/2000JD900310

Preunkert, S., Legrand, M., Jourdin, B., Moulin, C., Belviso, S., Kasamatsu, N., \& Hirawake, T. (2007). Interannual variability of dimethylsulfide in air and seawater and its atmospheric oxidation by-products (methanesulfonate and sulfate) at Dumont d'Urville, coastal Antarctica (1999-2003). Journal of Geophysical Research, 112(D6), 1-13. https://doi.org/10.1029/2006JD007585

Pye, H. O., Nenes, A., Alexander, B., Ault, A. P., Barth, M. C., Clegg, S. L., et al. (2020). The acidity of atmospheric particles and clouds. Atmospheric Chemistry and Physics, 20(8), 4809-4888. https://doi.org/10.5194/acp-20-4809-2020

Quinn, P. K., Bates, T. S., Schulz, K. S., Coffman, D. J., Frossard, A. A., Russell, L. M., et al. (2014). Contribution of sea surface carbon pool to organic matter enrichment in sea spray aerosol. Nature Geoscience, 7(3), 228-232. https://doi.org/10.1038/ngeo2092

Quinn, P. K., Coffman, D. J., Johnson, J. E., Upchurch, L. M., \& Bates, T. S. (2017). Small fraction of marine cloud condensation nuclei made up of sea spray aerosol. Nature Geoscience, 10(9), 674-679. https://doi.org/10.1038/ngeo3003

Quinn, P. K., Coffman, D. J., Kapustin, V. N., Bates, T. S., \& Covert, D. S. (1998). Aerosol optical properties in the marine boundary layer during the First Aerosol Characterization Experiment (ACE 1) and the underlying chemical and physical aerosol properties. Journal of Geophysical Research, 103(D13), 16547-16563. https://doi.org/10.1029/97JD02345

Regayre, L. A., Schmale, J., Johnson, J. S., Tatzelt, C., Baccarini, A., Henning, S., et al. (2020). The value of remote marine aerosol measurements for constraining radiative forcing uncertainty. Atmospheric Chemistry and Physics, 20(16), 10063-10072. https://doi.org/10.5194/ acp-20-10063-2020

Revell, L. E., Kremser, S., Hartery, S., Harvey, M., Mulcahy, J. P., Williams, J., et al. (2019). The sensitivity of Southern Ocean aerosols and cloud microphysics to sea spray and sulfate aerosol production in the HadGEM3-GA7.1 chemistry-climate model. Atmospheric Chemistry and Physics, 19(24), 15447-15466. https://doi.org/10.5194/acp-19-15447-2019

Riddick, S. N., Blackall, T. D., Dragosits, U., Daunt, F., Newell, M., Braban, C. F., et al. (2016). Measurement of ammonia emissions from temperate and sub-polar seabird colonies. Atmospheric Environment, 134, 40-50. https://doi.org/10.1016/j.atmosenv.2016.03.016

Riddick, S., Dragosits, U., Blackall, T., Daunt, F., Wanless, S., \& Sutton, M. (2012). The global distribution of ammonia emissions from seabird colonies. Atmospheric Environment, 55, 319-327. https://doi.org/10.1016/j.atmosenv.2012.02.052

Rinaldi, M., Paglione, M., Decesari, S., Harrison, R. M., Beddows, D. C. S., Ovadnevaite, J., et al. (2020). Contribution of water-soluble organic matter from multiple marine geographic eco-regions to aerosols around Antarctica. Environmental Science \& Technology, 54(13), 7807-7817. https://doi.org/10.1021/acs.est.0c00695

Saiz-Lopez, A., Blaszczak-Boxe, C. S., \& Carpenter, L. J. (2015). A mechanism for biologically induced iodine emissions from sea ice. Atmospheric Chemistry and Physics, 15(17), 9731-9746. https://doi.org/10.5194/acp-15-9731-2015

Saiz-Lopez, A., Fernandez, R. P., Ordóñez, C., Kinnison, D. E., Martín, J. C., Lamarque, J. F., \& Tilmes, S. (2014). Iodine chemistry in the troposphere and its effect on ozone. Atmospheric Chemistry and Physics, 14(23), 13119-13143. https://doi.org/10.5194/acp-14-13119-2014

Saiz-Lopez, A., Mahajan, A. S., Salmon, R. A., Bauguitte, S. J., Jones, A. E., Roscoe, H. K., \& Plane, J. M. (2007). Boundary layer halogens in coastal Antarctica. Science, 317(5836), 348-351. https://doi.org/10.1126/science.1141408

Saiz-Lopez, A., Plane, J. M. C., Baker, A. R., Carpenter, L. J., von Glasow, R., Gómez Martín, J. C., et al. (2012). Atmospheric chemistry of iodine. Chemical Reviews, 112(3), 1773-1804. https://doi.org/10.1021/cr200029u

Sanchez, K. J., Roberts, G. C., Saliba, G., Russell, L. M., Twohy, C., Reeves, J. M., et al. (2021). Measurement report: Cloud processes and the transport of biological emissions affect southern ocean particle and cloud condensation nuclei concentrations. Atmospheric Chemistry and Physics, 21(5), 3427-3446. https://doi.org/10.5194/acp-21-3427-2021

Savoie, D. L., Prospero, J. M., Larsen, R. J., Huang, F., Izaguirre, M. A., Huang, T., et al. (1993). Nitrogen and sulfur species in Antarctic aerosols at Mawson, Palmer Station, and Marsh (King George Island). Journal of Atmospheric Chemistry, 17(2), 95-122. https://doi. org/10.1007/bf00702821

Schmale, J., Baccarini, A., Thurnherr, I., Henning, S., Efraim, A., Regayre, L., et al. (2019). Overview of the antarctic circumnavigation expedition: Study of preindustrial-like aerosols and their climate effects (ACE-SPACE). Bulletin of the American Meteorological Society, 100(11), 2260-2283. https://doi.org/10.1175/10.1175/bams-d-18-0187.1

Schmale, J., Henning, S., Tummon, F., Hartmann, M., Baccarini, A., Welti, A., et al. (2019a). Coarse mode aerosol particle size distribution collected in the Southern Ocean in the austral summer of 2016/2017, during the Antarctic Circumnavigation Expedition. Zenodo. https:// doi.org/10.5281/ZENODO.2636709

Schmale, J., Henning, S., Tummon, F., Hartmann, M., Baccarini, A., Welti, A., et al. (2019b). Sub-micron aerosol particle size distribution collected in the Southern Ocean in the austral summer of 2016/2017, during the Antarctic Circumnavigation Expedition. Zenodo. Retrieved from https://zenodo.org/record/2636700

Schmale, J., Schneider, J., Nemitz, E., Tang, Y. S., Dragosits, U., Blackall, T. D., et al. (2013). Sub-Antarctic marine aerosol: Dominant contributions from biogenic sources. Atmospheric Chemistry and Physics, 13(17), 8669-8694. https://doi.org/10.5194/acp-13-8669-2013

Schmidt, A., Carslaw, K. S., Mann, G. W., Rap, A., Pringle, K. J., Spracklen, D. V., et al. (2012). Importance of tropospheric volcanic aerosol for indirect radiative forcing of climate. Atmospheric Chemistry and Physics, 12(16), 7321-7339. https://doi.org/10.5194/acp-12-7321-2012

Schobesberger, S., Franchin, A., Bianchi, F., Rondo, L., Duplissy, J., Kürten, A., et al. (2015). On the composition of ammonia-sulfuric-acid ion clusters during aerosol particle formation. Atmospheric Chemistry and Physics, 15(1), 55-78. https://doi.org/10.5194/acp-15-55-2015

Schönhardt, A., Richter, A., Wittrock, F., Kirk, H., Oetjen, H., Roscoe, H. K., \& Burrows, J. P. (2008). Observations of iodine monoxide columns from satellite. Atmospheric Chemistry and Physics, 8(3), 637-653. https://doi.org/10.5194/acp-8-637-2008

Seinfeld, J. H., \& Pandis, S. N. (2016). Atmospheric Chemistry and Physics: from Air Pollution to Climate Change. John Wiley \& Sons.

Sellegri, K., Nicosia, A., Freney, E., Uitz, J., Thyssen, M., Grégori, G., et al. (2021). Surface ocean microbiota determine cloud precursors. Scientific Reports, 11(1), 281. https://doi.org/10.1038/s41598-020-78097-5 
Sipilä, M., Sarnela, N., Jokinen, T., Henschel, H., Junninen, H., Kontkanen, J., et al. (2016). Molecular-scale evidence of aerosol particle formation via sequential addition of $\mathrm{HIO}_{3}$. Nature, 537(7621), 532-534. https://doi.org/10.1038/nature19314

Spracklen, D. V., Pringle, K. J., Carslaw, K. S., Mann, G. W., Manktelow, P., \& Heintzenberg, J. (2007). Evaluation of a global aerosol microphysics model against size-resolved particle statistics in the marine atmosphere. Atmospheric Chemistry and Physics, 7(8), 2073-2090. https://doi.org/10.5194/acp-7-2073-2007

Sprenger, M., \& Wernli, H. (2015). The LAGRANTO Lagrangian analysis tool - Version 2.0. Geoscientific Model Development, 8(8), 25692586. https://doi.org/10.5194/gmd-8-2569-2015

Stocker, T. F., Qin, D., Plattner, G.-K., Tignor, M. M. B., Allen, S. K., Boschung, J., \& Midgley, P. M. (2014). Climate Change 2013: The physical science basis. contribution of working group I to the fifth assessment report of IPCC the intergovernmental panel on climate change. Cambridge University Press. Retrieved from https://www.ipcc.ch/report/ar5/wg1/

Tatzelt, C., Henning, S., Tummon, F., Hartmann, M., Baccarini, A., Welti, A., et al. (2020). Ionic composition of particulate matter (PM10) from high-volume sampling over the Southern Ocean during the austral summer of 2016/2017 on board the Antarctic Circumnavigation Expedition (ACE). Zenodo. Retrieved from https://zenodo.org/record/3922147

Teinilä, K., Kerminen, V. M., \& Hillamo, R. (2000). A study of size-segregated aerosol chemistry in the Antarctic atmosphere. Journal of Geophysical Research, 105(D3), 3893-3904. https://doi.org/10.1029/1999JD901033

Thurnherr, I., Wernli, H., \& Aemisegger, F. (2020). 10-day backward trajectories from ECMWF analysis data along the ship track of the Antarctic Circumnavigation Expedition in austral summer 2016/2017. Zenodo. https://doi.org/10.5281/zenodo.4031704

Uetake, J., Hill, T. C. J., Moore, K. A., DeMott, P. J., Protat, A., \& Kreidenweis, S. M. (2020). Airborne bacteria confirm the pristine nature of the Southern Ocean boundary layer. Proceedings of the National Academy of Sciences, 117(24), 13275-13282. https://doi.org/10.1073/ pnas. 2000134117

Virkkula, A., Teinilä, K., Hillamo, R., Kerminen, V.-M., Saarikoski, S., Aurela, M., et al. (2006). Chemical composition of boundary layer aerosol over the Atlantic Ocean and at an Antarctic site. Atmospheric Chemistry and Physics, 6(11), 3407-3421. https://doi.org/10.5194/ acp-6-3407-2006

Walton, D. W. H., \& Thomas, J. (2018). Cruise Report - Antarctic Circumnavigation Expedition (ACE) 20 th December 2016 - 19 th March 2017 (Tech. Rep.). Swiss Polar Institute. Retrieved from https://zenodo.org/record/1443511

Weber, R. J., McMurry, P. H., Mauldin, L., Tanner, D. J., Eisele, F. L., Brechtel, F. J., et al. (1998). A study of new particle formation and growth involving biogenic and trace gas species measured during ACE 1. Journal of Geophysical Research: Atmospheres, 103(D13), 16385-16396. https://doi.org/10.1029/97jd02465

Weingartner, E., Nyeki, S., \& Baltensperger, U. (1999). Seasonal and diurnal variation of aerosol size distributions ( $\mathrm{nm}$ ) at a high-alpine site (Jungfraujoch 3580 m asl). Journal of Geophysical Research, 104(D21), 26809-26820. https://doi.org/10.1029/1999JD900170

Weller, R., Schmidt, K., Teinilä, K., \& Hillamo, R. (2015). Natural new particle formation at the coastal Antarctic site Neumayer. Atmospheric Chemistry and Physics, 15(19), 11399-11410. https://doi.org/10.5194/acp-15-11399-2015

Wexler, A. S., \& Clegg, S. L. (2002). Atmospheric aerosol models for systems including the ions $\mathrm{H}^{+}, \mathrm{NH}_{4}^{+}, \mathrm{NA}^{+}, \mathrm{SO}_{4}^{2-}, \mathrm{NO}_{3}^{-}, \mathrm{Cl}^{-}, \mathrm{Br}^{-}$, and $\mathrm{H}_{2} \mathrm{O}$. Journal of Geophysical Research, 107(D14), ACH 14-1-ACH 14-14. https://doi.org/10.1029/2001JD000451

Williams, J., de Reus, M., Krejci, R., Fischer, H., \& Ström, J. (2002). Application of the variability-size relationship to atmospheric aerosol studies: Estimating aerosol lifetimes and ages. Atmospheric Chemistry and Physics, 2(2), 133-145. https://doi.org/10.5194/acp-2-133-2002

Xu, G., Gao, Y., Lin, Q., Li, W., \& Chen, L. (2013). Characteristics of water-soluble inorganic and organic ions in aerosols over the Southern Ocean and coastal East Antarctica during austral summer. Journal of Geophysical Research: Atmospheres, 118, 13318(23), 13,303-13,318. https://doi.org/10.1002/2013JD019496

Yan, J., Jung, J., Zhang, M., Bianchi, F., Jun Tham, Y., Xu, S., et al. (2020). Uptake selectivity of methanesulfonic acid (MSA) on fine particles over polynya regions of the Ross Sea, Antarctica. Atmospheric Chemistry and Physics, 20(5), 3259-3271. https://doi.org/10.5194/ acp-20-3259-2020

Yan, J., Jung, J., Zhang, M., Xu, S., Lin, Q., Zhao, S., \& Chen, L. (2019). Significant underestimation of gaseous methanesulfonic acid (MSA) over Southern Ocean. Environmental Science and Technology, 53(22), 13064-13070. https://doi.org/10.1021/acs.est.9b05362

Yoon, Y. J., \& Brimblecombe, P. (2002). Modelling the contribution of sea salt and dimethyl sulfide derived aerosol to marine CCN. Atmospheric Chemistry and Physics, 2(1), 17-30. https://doi.org/10.5194/acp-2-17-2002

Zorn, S. R., Drewnick, F., Schott, M., Hoffmann, T., \& Borrmann, S. (2008). Characterization of the South Atlantic marine boundary layer aerosol using an aerodyne aerosol mass spectrometer. Atmospheric Chemistry and Physics, 8(16), 4711-4728. https://doi.org/10.5194/ acp-8-4711-2008

\section{References From the Supporting Information}

Clarke, J. H. R., \& Woodward, L. A. (1966). Raman spectrophotometric determination of the degrees of dissociation of methanesulphonic acid in aqueous solution at 25C. Transactions of the Faraday Society, 62, 2226-2233. https://doi.org/10.1039/TF9666202226

Clegg, S., \& Brimblecombe, P. (1985). The solubility of methanesulphonic acid and its implications for atmospheric chemistry. Environmental Technology Letters, 6(1-11), 269-278. https://doi.org/10.1080/09593338509384344

Clegg, S. L., \& Seinfeld, J. H. (2006). Thermodynamic Models of Aqueous Solutions Containing Inorganic Electrolytes and Dicarboxylic Acids at 298.15 K. 1. The Acids as Nondissociating Components. The Journal of Physical Chemistry A, 110(17), 5692-5717. https://doi. $\operatorname{org} / 10.1021 / \mathrm{jp} 056149 \mathrm{k}$

Dutcher, C. S., Wexler, A. S., \& Clegg, S. L. (2010). Surface Tensions of Inorganic Multicomponent Aqueous Electrolyte Solutions and Melts. The Journal of Physical Chemistry A, 114(46), 12216-12230. https://doi.org/10.1021/jp105191z

Eisele, F. L., \& Tanner, D. J. (1993). Measurement of the gas phase concentration of $\mathrm{H}_{2} \mathrm{SO}_{4}$ and methane sulfonic acid and estimates of $\mathrm{H}_{2} \mathrm{SO}_{4}$ production and loss in the atmosphere. Journal of Geophysical Research, 98(D5), 9001-9010. https://doi.org/10.1029/93JD00031

Kramp, F., \& Paulson, S. E. (1998). On the uncertainties in the rate coefficients for OH reactions with hydrocarbons, and the rate coefficients of the 1, 3,5-trimethylbenzene and m-xylene reactions with $\mathrm{OH}$ radicals in the gas phase. Journal of Physical Chemistry A, 102(16), 2685-2690. https://doi.org/10.1021/jp973289o

Myhre, C. E. L., D'Anna, B., Nicolaisen, F. M., \& Nielsen, C. J. (2004). Properties of aqueous methanesulfonic acid: Complex index of refraction and surface tension. Applied Optics, 43(12), 2500. https://doi.org/10.1364/AO.43.002500

Wine, P. H., Thompson, R. J., Ravishankara, A. R., Semmes, D. H., Gump, C. A., Torabi, A., \& Nicovich, J. M. (1984). Kinetics of the reaction $\mathrm{OH}+\mathrm{SO}_{2}+\mathrm{M} \rightarrow \mathrm{HOSO}_{2}+\mathrm{M}$. Temperature and pressure dependence in the fall-off region. The Journal of Physical Chemistry, 88(10), 2095-2104. https://doi.org/10.1021/j150654a031 